\title{
MONETARY POLICY AND SOVEREIGN DEBT VULNERABHLTY
}

Revised version: September 2015

Galo Nuno and carlos thomas.

\section{5}

Documentos de Trabajo. N. 1517

\section{BANCODEESPANA}

\author{
Eurosistema
}

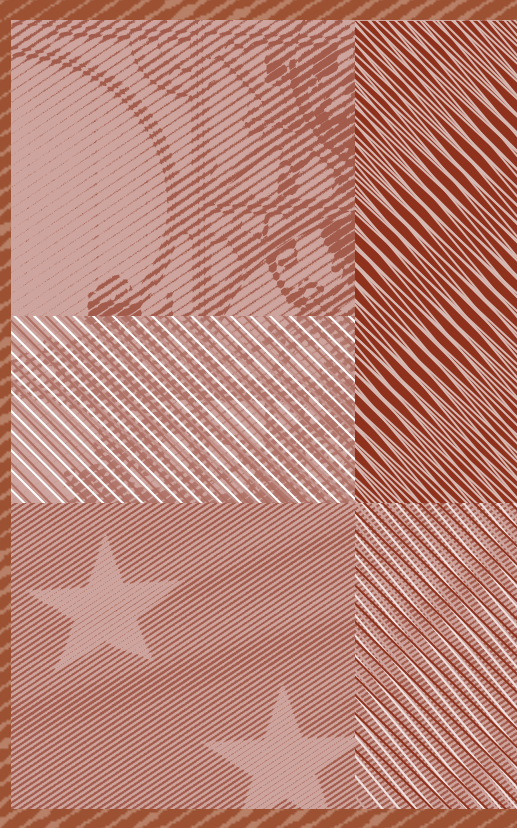


MONETARY POLICY AND SOVEREIGN DEBT VULNERABILITY 
MONETARY POLICY AND SOVEREIGN DEBT VULNERABILITY

Galo Nuño

BANCO DE ESPAÑA

Carlos Thomas

BANCO DE ESPAÑA

${ }^{*}$ ) The views expressed in this paper are those of the authors and do not necessarily represent the views of Banco de España or the Eurosystem. The authors are very grateful to Fernando Álvarez, Manuel Amador, Óscar Arce, Antoine Camous, Giancarlo Corsetti, Jose A. Cuenca, Luca Dedola, Aitor Erce, Maurizio Falcone, Esther Gordo, Alfredo Ibañez, Fabio Kanczuk, Peter Karadi, Xiaowen Lei, Benjamin Moll, Pedro Teles, Juan Pablo Rincón-Zapatero, conference participants at the European Winter Meetings of the Econometric Society, Theories and Methods in Macroeconomics Conference, Banco do Brasil Annual Inflation Targeting Seminar and Barcelona GSE Summer Forum, and seminar participants at Banca d'Italia, BBVA, Banco de España, European Commission, Universidad de Vigo, ECB, and University of Porto for helpful comments and suggestions. All remaining errors are ours. 
The Working Paper Series seeks to disseminate original research in economics and finance. All papers have been anonymously refereed. By publishing these papers, the Banco de España aims to contribute to economic analysis and, in particular, to knowledge of the Spanish economy and its international environment.

The opinions and analyses in the Working Paper Series are the responsibility of the authors and, therefore, do not necessarily coincide with those of the Banco de España or the Eurosystem.

The Banco de España disseminates its main reports and most of its publications via the Internet at the following website: http://www.bde.es.

Reproduction for educational and non-commercial purposes is permitted provided that the source is acknowledged.

C BANCO DE ESPAÑA, Madrid, 2015

ISSN: 1579-8666 (on line) 


\section{Abstract}

We investigate the trade-offs between price stability and the sustainability of sovereign debt, using a small open economy model where the government issues nominal defaultable debt and chooses fiscal and monetary policy under discretion. When choosing inflation, the government trades off the reduction in the real value of debt -which makes it more sustainable- against the welfare costs of inflation. We compare this scenario with one in which the government gives up the ability to deflate debt away, e.g. by issuing foreign currency debt or joining a monetary union with an anti-inflationary stance. We find that the benefits of abandoning debt deflation outweigh the costs, even when the economy is close to default. Crucially, the increase in inflation expectations and hence in nominal yields produced by discretionary monetary policy largely undoes the debt deflation effect.

Keywords: monetary- fiscal interactions, discretion, sovereign default, continuous time, optimal stopping.

JEL classification: E5, E62,F34. 


\section{Resumen}

En este trabajo investigamos la interacción entre estabilidad de precios y sostenibilidad de la deuda soberana en el marco de un modelo de pequeña economía abierta, en la cual el gobierno emite deuda nominal y elige la política fiscal y monetaria bajo discreción. La inflación reduce el valor real de la deuda, lo cual la hace más sostenible; pero también eleva sus rendimientos nominales y conlleva costes directos de bienestar. Comparamos este escenario con una situación en la cual el gobierno renuncia a la posibilidad de deflactar la deuda: por ejemplo, emitiendo deuda en moneda extranjera o incorporándose a una unión monetaria con un mandato anti-inflacionista. Encontramos que los beneficios de renunciar a dicho margen de ajuste dominan a los costes, tanto para nuestra calibración base como para un amplio rango de parámetros. Ello es debido a que el aumento de las expectativas de inflación y por tanto de los rendimientos nominales producido por la política monetaria discrecional compensa parcialmente los efectos de la deflación de la deuda.

Palabras clave: interacción monetaria-fiscal, discrecionalidad, impago soberano, tiempo continuo, parada óptima.

Códigos JEL: E5, E62,F34. 


\section{Introduction}

One of the main legacies of the 2007-9 financial crisis and the subsequent recession has been the emergence of large fiscal deficits across the industrialized world. The consequence has been a sharp increase in government debt, with debt-to-GDP ratios near or above record levels in countries such as the United States, United Kingdom, Japan or the Euro area periphery (Greece, Ireland, Italy, Portugal, Spain). Before the summer of 2012, Euro area periphery economies experienced dramatic spikes in their sovereign yields, whereas other highly indebted countries did not. Many observers emphasized that a key difference between both groups of countries was that, whereas the US, UK and Japan had the option to deflate away the real burden of nominal debt though inflation, the Euro countries were forced to repay debt solely through fiscal surpluses. At the same time, the experience of a number of developing countries such as Mexico or Brazil, in which large portions of sovereign debt are issued directly in foreign currency, illustrates situations in which governments sometimes renounce the possibility of deflating away their debt.

These developments raise the question as to what role monetary policy should have, if any, in guaranteeing the sustainability of sovereign debt, in view of the existing trade-offs between the latter and price stability. Broadly speaking, on the one hand it can be argued that central banks should provide a 'monetary brake' that reassures investors in sovereign debt. ${ }^{1}$ On the other hand, such a course of action may presumably give rise to inflation, with the resulting costs and distortions. Moreover, while using inflation temporarily for debt-deflation purposes may not largely affect inflation expectations in countries (such as the US or UK) where monetary authorities are perceived to have a clear and credible commitment towards price stability, the same may not be true in countries with a poorer inflation record and/or weaker monetary credibility, thus limiting the effectiveness of debt deflation policies.

In this paper, we try to shed light on the above issues by studying the trade-offs between price stability and sovereign debt sustainability when the government cannot make credible commitments about inflation. With this purpose, we build a general equilibrium, continuous-time model of a small open economy in which a benevolent government issues long-term sovereign nominal bonds to foreign investors. At any time, the government may default on its debt if it finds it optimal to do so. Default produces some costs due to temporary exclusion from capital markets and a drop in the output endowment. We show that the default decision is characterized by an optimal default threshold for the model's single state variable, the debt-to-GDP ratio. In addition, the government chooses fiscal and monetary policy optimally under discretion. That is, the government cannot commit to a future path for primary deficit and inflation. When choosing inflation, the government trades off benefits and costs. On the one hand, inflation reduces the real value of debt; ceteris

\footnotetext{
${ }^{1}$ This view is shared e.g. by Krugman (2011) or De Grauwe (2011).
} 
paribus, this improves sovereign debt sustainability by making default a less likely outcome. On the other hand, inflation entails a direct welfare cost. Moreover, expectations of future inflation worsen such trade-off by raising nominal yields for new bond issuances, thus making primary deficits more costly to finance.

We calibrate our model to capture some salient features of the EMU periphery economies, including their observed inflation record prior to joining the euro. Under our baseline calibration, the optimal inflation policy function increases roughly linearly with the debt ratio, and then increases steeply as the latter approaches the optimal default threshold. Importantly, the government allows for relatively high inflation rates at debt ratios for which default is still perceived as rather distant by investors. We refer to this baseline scenario as the 'inflationary regime'.

We then compare the baseline inflationary regime with a scenario in which inflation is zero at all times. In other words, the government effectively renounces the possibility of deflating debt away. Given our assumption that the government cannot make credible inflation commitments, this 'no inflation' regime is best interpreted as a situation in which the government directly issues foreign currency debt, or in which it joins a monetary union with a very strong and credible antiinflationary stance. We find that welfare in the no-inflation regime is higher at any debt ratio. The reason is that the no-inflation regime avoids the costs of inflation while barely compromising the sustainability of sovereign debt. Indeed, while renouncing the option to deflate debt away does make debt more vulnerable by making default more likely, such an event is still perceived as rather distant by investors at all debt ratios except for those very close to default. As a result, the (small) increase in risk premia vis-à-vis the inflationary regime is clearly dominated by the elimination of the inflation premia, with the ensuing reduction in bond yields. Moreover, even at relatively high debt ratios, the beneficial effects of inflation on debt sustainability are largely undone by the increase in nominal yields. ${ }^{2}$

Having characterized equilibrium in both regimes at each point of the state space, we then compute the stationary distribution of the main variables so as to analyze the average performance of both regimes. Since value functions in both regimes are strictly decreasing in debt ratios, the inflationary regime could in principle yield higher average welfare by delivering sufficiently lower debt most of the time. We find that the inflationary regime indeed shifts the distribution of the debt ratio to the left vis-à-vis the no-inflation one, reflecting the debt deflation effect. However, this shift is too small to overturn the state-by-state dominance of the no inflation regime. The reason, again, is that the debt deflation effect is mostly compensated by the increase in nominal yields. With the debt deflation channel thus weakened, the direct welfare costs of inflation become

\footnotetext{
${ }^{2}$ We also find that optimal default thresholds are nearly identical in both regimes, and that welfare under noinflation is higher too at such threshold. Intuitively, the prospect of defaulting is less favorable in the inflationary regime, because following the exclusion period the government returns to capital markets with basically the same debt burden as in the no-inflation regime, only with lower welfare due to the inflationary distortions.
} 
the dominant effect on welfare outcomes. As a consequence, the inflationary regime produces a loss in average welfare relative to the no-inflation scenario, one that is of first-order magnitude in our baseline calibration. We show that our findings are robust to a wide range of alternative parameter values.

Finally, as an alternative to giving up the debt deflation margin altogether, we investigate an intermediate arrangement in which the government delegates monetary policy to an independent central banker with a greater distaste for inflation than society as a whole. We find that delegating monetary policy to such a 'conservative' central banker allows achieving superior welfare outcomes vis-à-vis the baseline inflationary regime, in which the benevolent government chooses inflation discretionarily. As it turns out, however, average welfare never reaches that of the 'no inflation' regime: it increases monotonically with the central banker's distaste for inflation, converging asymptotically to its level under the latter regime.

Taken together, our results offer an important qualification of the conventional wisdom that individual countries may benefit from retaining the option to deflate away their sovereign debt. In particular, our analysis suggests that such countries may actually be better off by renouncing such a tool if their governments are unable to make credible commitments about their future inflation policy. This qualification may be relevant for most EMU peripheral economies, in view of their inflation record (relative e.g. to that of Germany) in the decades prior to joining the euro. Our findings may also rationalize why a number of developing countries with limited inflation credibility typically resort to issuing debt in terms of a hard foreign currency.

Literature review. Our paper relates to a recent theoretical literature that analyzes the link between sovereign debt vulnerability and monetary policy. One strand of this literature considers models of self-fulfilling debt crises, typically along the lines of Calvo (1988) or Cole and Kehoe (2000); see e.g. Aguiar et al. (2013), Reis (2013), Corsetti and Dedola (2014), Camous and Cooper (2014), and Bacchetta, Perazzi and van Wincoop (2015). We complement this literature by considering a framework in which sovereign default is instead an optimal government decision based on fundamentals, in the tradition of Eaton and Gersovitz (1981). ${ }^{3}$ Also, most of the above contributions are qualitative, working in environments with two periods or two-period-lived agents (Corsetti and Dedola, 2014; Camous and Cooper, 2014) or without fundamental uncertainty (Aguiar et al., 2013). ${ }^{4}$ By contrast, we adopt a fully dynamic, stochastic approach, which makes

\footnotetext{
${ }^{3}$ In Corsetti and Dedola (2014) default crisis can also be due to weak fundamentals.

${ }^{4}$ An exception is Bachetta et al. (2014), who explore quantitatively a monetary version of Lorenzoni and Werning's (2014) 'slow moving' debt crisis model, which in turn extends the Calvo (1998) framework to a dynamic setting. In their baseline model, fundamental uncertainty is restricted to the present value of primary surpluses from a known future date onwards. They also consider an extension in which the date at which the surplus uncertainty is resolved is itself random. The connection between inflation and the possibility of self-fulfilling debt crisis in fully dynamic, stochastic frameworks is also analyzed in Da Rocha et al. (2013) and Araujo et al. (2013). Da Rocha et al. (2013) analyze optimal debt and exchange rate policy in a model with foreign currency debt where the government is exposed to both self-fulfilling defaults and devaluations. Araujo et al. (2013) consider the welfare gains or losses
} 
our model potentially useful for quantitative analysis. In particular, we show that our model can replicate well average sovereign yields and risk premia in the peripheral EMU economies, while also matching average external sovereign debt stocks. We also show that our model can rationalize the reduction in sovereign bond yields across EMU periphery countries relative to the pre-EMU period, which suggests that investors perceived the reduction in inflation expectations as more important than the presumable increase in default risk.

Our modeling of inflation disutility costs is based on Aguiar et al. (2013), who interpret the weight on such disutility in government preferences as the government's 'inflation credibility'. ${ }^{5}$ These authors find that, under certain conditions (such as a moderate inflation credibility and intermediate debt levels), issuing domestic currency debt and deflating it at discretion may achieve superior welfare outcomes relative to issuing foreign currency debt. By contrast, we find that issuing foreign currency debt outperforms issuing domestic currency debt for any debt ratio, even when the economy is close to default. In our analysis of monetary policy delegation, we similarly find that abandoning debt deflation produces higher average welfare regardless of the monetary authority's distaste for inflation.

In modeling optimal default à la Eaton-Gersovitz in a quantitative framework, our model is more in line with the literature on quantitative sovereign default models initiated by Aguiar and Gopinath (2006) and Arellano (2008). ${ }^{6}$ We build on this literature by introducing nominal bonds and studying the optimal inflation policy when the government cannot commit not to inflate in the future. This allows us to address the trade-offs between price stability and sovereign debt vulnerability in a unified framework. ${ }^{7}$ Another difference with respect to the quantitative sovereign default literature is our reliance on continuous time. Continuous-time methods are standard in the corporate default literature initiated by Merton (1974) and Leland (1994) due to their tractability. ${ }^{8}$ We show how one can extend this analysis to the pricing of defaultable nominal sovereign debt.

from issuing debt in local versus foreign currency, in a framework where the costs of local currency debt are due to an exogenous inflation shock.

${ }^{5}$ In an environment similar to Aguiar et al. (2013), Aguiar et al. (2015) study the impact of the composition of debt in a monetary union on the occurrence of self-fulfilling debt crises. One important difference between Aguiar et al. $(2013,2015)$ and our paper is that we consider quadratic (as opposed to linear) inflation costs, which allows us to obtain interior solutions for optimal inflation.

${ }^{6}$ Other notable contributions to this literature include Benjamin and Wright (2009), Chatterjee and Eyigungor (2012), Hatchondo and Martínez (2009) and Yue (2010). Mendoza and Yue (2012) integrate an optimal sovereign default model into a standard real business cycle framework with endogenous production.

${ }^{7}$ Other papers introducing nominal debt and monetary policy in sovereign default models à la Aguiar-Gopinath (2006) and Arellano (2008) are Sunder-Plassmann (2014) and Du and Schreger (2015). Sunder-Plassmann (2014) studies how the denomination of sovereign debt (nominal vs. real/foreign currency) affects the government's incentives to inflate or default on its debt, in a model with monetary frictions. Du and Schreger (2015) analyze how the share of local vs. foreign currency debt in overall corporate debt determines the sovereign's incentive to inflate or default on its own debt when the latter is denominated in local currency, in a framework where firms face borrowing constraints and a currency mismatch between revenues and liabilities.

${ }^{8}$ See Sundaresan (2013) for a survey of this literature. 
In studying the effects of delegating monetary policy to an independent, conservative central banker, our analysis revisits an old theme initiated by Rogoff (1985) and further discussed e.g. in Clarida, Galí and Gertler (1999), although it does so in a very different context. ${ }^{9}$ In particular, we explore the effects of delegation in a framework in which the benefit of allowing for inflation is not to exploit a short-run output/inflation trade-off, as in the mainstream New Keynesian literature, but rather to make sovereign debt more sustainable. Contrary to the linear(ized) frameworks typically used in the New Keynesian literature, our framework takes full account of the strong non-linearities that emerge in the presence of equilibrium sovereign default. As in that literature, we find that there are welfare gains from delegating discretionary monetary policy to an independent authority with a greater distaste for inflation than that of society. What is perhaps more striking is that, whereas the optimal 'delegated' inflation distaste in the above literature is relatively large but finite, in our framework welfare is maximized when such distaste is arbitrarily large, i.e. when the government completely abandons the option of adjusting inflation.

Finally, we make a technical contribution by introducing a new numerical method to find the equilibrium in continuous-time models with several agents. In particular we extend the recent literature about finite difference methods applied to stochastic control in economics, such as Achdou et al. (2014) or Nuño and Moll (2014), to analyze a recursive optimal stopping problem in which one of the agents (in our case, the government) employs both continuously chosen controls and discrete adjustments of the state variables. Optimal stopping problems are typically solved using optimal splitting methods, as in Barles, Daher and Romano (1995). However, the recursivity of our problem and the fact that it only has one state variable allows us to employ the so-called "smooth pasting" and "value matching" conditions to numerically find the default threshold.

The structure of the paper is as follows. In section 2 we introduce the model. Section 3 provides the main results. In Section 4 we perform some robustness analyses. Section 5 introduces monetary policy delegation. Section 6 concludes.

\section{$2 \quad$ Model}

We consider a continuous-time model of a small open economy.

\subsection{Output, price level and sovereign debt}

Let $\left(\Omega, \mathcal{F},\left\{\mathcal{F}_{t}\right\}, \mathbb{P}\right)$ be a filtered probability space. There is a single, freely-traded consumption good which has an international price normalized to one. The economy is endowed with $Y_{t}$ units

\footnotetext{
${ }^{9}$ Lohmann (1992) generalizes Rogoff's analysis by considering a conservative central banker that can be overriden by the government in the presence of extremely large shocks.
} 
of the good each period (real GDP). The evolution of $Y_{t}$ is given by

$$
d Y_{t}=\mu Y_{t} d t+\sigma Y_{t} d W_{t}
$$

where $W_{t}$ is a $\mathcal{F}_{t}$-Brownian motion, $\mu \in \mathbb{R}$ is the drift parameter and $\sigma \in \mathbb{R}_{+}$is the volatility. The local currency price relative to the World price at time $t$ is denoted $P_{t}$. It evolves according to

$$
d P_{t}=\pi_{t} P_{t} d t
$$

where $\pi_{t}$ is the instantaneous inflation rate.

The government trades a nominal non-contingent bond with risk-neutral competitive foreign investors. Let $B_{t}$ denote the outstanding stock of nominal government bonds; assuming that each bond has a nominal value of one unit of domestic currency, $B_{t}$ also represents the total nominal value of outstanding debt. We assume that outstanding debt is amortized at rate $\lambda>0$ per unit of time. The nominal value of outstanding debt thus evolves as follows,

$$
d B_{t}=B_{t}^{\text {new }} d t-\lambda d t B_{t}
$$

where $B_{t}^{\text {new }}$ is the flow of new debt issued at time $t$. The nominal market price of government bonds at time $t$ is $Q_{t}$. Each bond pays a proportional coupon $\delta$ per unit of time. Also, the government incurs a nominal primary deficit $P_{t}\left(C_{t}-Y_{t}\right)$, where $C_{t}$ is aggregate consumption. ${ }^{10}$ The government's flow of funds constraint is then

$$
Q_{t} B_{t}^{\text {new }}=(\lambda+\delta) B_{t}+P_{t}\left(C_{t}-Y_{t}\right)
$$

That is, the proceeds from issuance of new bonds must cover amortization and coupon payments plus the primary deficit. Combining the last two equations, we obtain the following dynamics for nominal debt outstanding,

$$
d B_{t}=\left[\left(\frac{\lambda+\delta}{Q_{t}}-\lambda\right) B_{t}+\frac{P_{t}}{Q_{t}}\left(C_{t}-Y_{t}\right)\right] d t
$$

We define the debt-to-GDP ratio as $b_{t} \equiv B_{t} /\left(P_{t} Y_{t}\right)$. Its dynamics are obtained by applying Itô's lemma to equations (1)-(3),

$$
d b_{t}=\left[\left(\frac{\lambda+\delta}{Q_{t}}-\lambda+\sigma^{2}-\mu-\pi_{t}\right) b_{t}+\frac{c_{t}}{Q_{t}}\right] d t-\sigma b_{t} d W_{t}
$$

\footnotetext{
${ }^{10}$ As in Arellano (2008), we assume that the government rebates back to households all the net proceedings from its international credit operations (i.e. its primary deficit) in a lump-sum fashion. Denoting by $T_{t}$ the primary deficit, we thus have $P_{t} C_{t}=P_{t} Y_{t}+T_{t}$. This implies $T_{t}=P_{t}\left(C_{t}-Y_{t}\right)$.
} 
where $c_{t} \equiv\left(C_{t}-Y_{t}\right) / Y_{t}$ is the primary deficit-to-GDP ratio. Equation (4) describes the evolution of the debt-to-GDP ratio as a function of the primary deficit ratio, inflation and the bond price. In particular, ceteris paribus inflation $\pi_{t}$ allows to reduce the debt ratio by reducing the real value of nominal debt. We also impose a non-negativity constraint on debt: $b_{t} \geq 0$.

\subsection{Preferences}

The representative household has preferences over paths for consumption and domestic inflation given by

$$
U_{0} \equiv \mathbb{E}_{0}\left[\int_{0}^{\infty} e^{-\rho t} u\left(C_{t}, \pi_{t}\right) d t\right]
$$

We assume that instantaneous utility takes the form

$$
u\left(C_{t}, \pi_{t}\right)=\log \left(C_{t}\right)-\frac{\psi}{2} \pi_{t}^{2},
$$

where $\psi>0$. We follow Aguiar et al. (2013) in posing a reduced-form specification for the welfare costs of inflation, $(\psi / 2) \pi_{t}^{2}$. Unlike in Aguiar et al. (2013), though, we consider a quadratic functional form, which allows us to obtain interior solutions for optimal inflation. ${ }^{11} \mathrm{Using} C_{t}=$ $\left(1+c_{t}\right) Y_{t}$, we can express welfare in terms of the primary deficit ratio $c_{t}$ as follows,

$$
\begin{aligned}
U_{0} & =\mathbb{E}_{0}\left[\int_{0}^{\infty} e^{-\rho t}\left(\log \left(1+c_{t}\right)+\log \left(Y_{t}\right)-\frac{\psi}{2} \pi_{t}^{2}\right) d t\right] \\
& =\mathbb{E}_{0}\left[\int_{0}^{\infty} e^{-\rho t}\left(\log \left(1+c_{t}\right)-\frac{\psi}{2} \pi_{t}^{2}\right) d t\right]+V_{0}^{\text {aut }}
\end{aligned}
$$

where

$$
V_{0}^{\text {aut }} \equiv \mathbb{E}_{0}\left[\int_{0}^{\infty} e^{-\rho t} \log \left(Y_{t}\right) d t\right]=\frac{\log \left(Y_{0}\right)}{\rho}+\frac{\mu-\sigma^{2} / 2}{\rho^{2}}
$$

is the (exogenous) value at time $t=0$ of being in autarky forever. ${ }^{12}$ Thus, welfare increases with the primary deficit ratio $c_{t}$, as this allows households to consume more for a given exogenous output; and it decreases with squared inflation deviations from zero.

\footnotetext{
${ }^{11}$ Aguiar et al. (2013) adopt instead a linear inflation disutility, and restrict inflation to be within a closed interval. As explained by the authors, this gives rise to bang-bang inflation equilibria.

${ }^{12}$ Notice that (1) and Itô's Lemma imply $d \log Y_{t}=\left(\mu-\sigma^{2} / 2\right) d t+\sigma d W_{t}$. Solving for $\log Y_{t}$ and taking time-0 conditional expectations yields $\mathbb{E}_{0}\left(\log Y_{t}\right)=\log Y_{0}+\left(\mu-\sigma^{2} / 2\right) t$, which combined with the definition of $V_{0}^{\text {aut }}$ gives us the right-hand side of (8).
} 


\subsection{Fiscal and monetary policy}

The government chooses fiscal policy at each point in time along two dimensions: it sets optimally the primary surplus ratio $c_{t}$, and it chooses whether to continue honoring debt repayments or else to default. In addition, the government implements monetary policy by choosing the inflation rate $\pi_{t}$ at each point in time. We now present the sovereign default scenario, which affects the boundary conditions of the general optimization problem.

\subsubsection{The default scenario}

In case of default, the government suffers a double punishment. First, it is excluded from international capital markets temporarily. The duration of this exclusion period, $\tau$, is random and follows an exponential distribution with average duration $1 / \chi$. Second, during the exclusion period the country's output endowment declines. Suppose the government defaults at an arbitrary debt ratio $b$. Then during the exclusion period the country's output endowment is given by $Y_{t}^{\text {def }}=Y_{t} \exp [-\epsilon \max \{0, b-\hat{b}\}]$, with $\epsilon, \hat{b}>0$, such that the loss in (log)output equals $\epsilon \max \{0, b-\hat{b}\}$. Therefore, the country suffers an output loss only if it defaults at a debt ratio higher than a threshold $\hat{b}$. This specification of output loss is similar to the one in Arellano (2008). ${ }^{13}$ During the exclusion phase, households simply consume the output endowment, $C_{t}=Y_{t}^{\text {def }}$, which implies

$$
\log \left(C_{t}\right)=\log \left(Y_{t}\right)-\epsilon \max \{0, b-\hat{b}\} .
$$

The main advantage of defaulting is of course the possibility of reducing the debt burden. During the exclusion period, which we may interpret as a renegotiation process between the government and the investors, the latter receive no repayments. Let $\hat{t}$ denote the time of the most recent default. We assume that at the end of the exclusion period, i.e. at time $\hat{t}+\tau$, both parties reach an agreement by which investors recover a fraction $\theta Y_{\hat{t}+\tau} P_{\hat{t}+\tau} /\left(Y_{\hat{t}} P_{\hat{t}}\right)$ of the nominal value of outstanding bonds at the time of default, for some parameter $\theta>0 .{ }^{14}$ This specification captures in reduced form the idea that the terms of the debt restructuring agreement are somehow sensitive to the country's macroeconomic performance. ${ }^{15}$ Importantly, it allows us to keep the set of state variables restricted to the debt ratio only. To see this, notice that upon regaining access to capital

\footnotetext{
${ }^{13}$ In Arellano (2008), the output loss following default equals $Y_{t}-Y_{t}^{\text {def }}=\max \left\{0, Y_{t}-\hat{Y}\right\}$, for some threshold output level $\hat{Y}$. Specifying our output loss function in terms of $b_{t}$ (as opposed to $Y_{t}$ ) allows us to retain the convenient model feature that $b_{t}$ is the only relevant state variable.

${ }^{14}$ Notice that $Y_{\hat{t}}$ and $Y_{\hat{t}+\tau}$ represent, respectively, the output levels exactly at the time the government decides to default (i.e. right before output drops) and exactly upon regaining access to capital markets ( i.e. right after output recovers again). Therefore, they do not incorporate the output loss during exclusion.

${ }^{15}$ See Benjamin and Wright (2009) and Yue (2010) for studies that endogenize the recovery rate upon default, in models with explicit renegotiation betwen the government and its creditors.
} 
markets, the debt ratio is

$$
b_{\hat{t}+\tau}=\left(\theta \frac{Y_{\hat{t}+\tau} P_{\hat{t}+\tau}}{Y_{\hat{t}} P_{\hat{t}}}\right) B_{\hat{t}} \frac{1}{Y_{\hat{t}+\tau} P_{\hat{t}+\tau}}=\theta b_{\hat{t}}
$$

where $b_{\hat{t}}=B_{\hat{t}} / Y_{\hat{t}} P_{\hat{t}}$ is the debt ratio at the time of default. Therefore, the government reenters capital markets with a debt ratio that is a fraction $\theta$ of the ratio at which it defaulted. It follows that the government has no incentive to create inflation during the exclusion period, as that would generate direct welfare costs while not reducing the debt ratio upon reentry; we thus have $\pi_{t}=0$ for $t \in(\hat{t}, \hat{t}+\tau)$.

Taking all these elements together, we can express the value of defaulting at $\hat{t}=0$ as $U_{0}^{\text {def }}=$ $V_{0}^{\text {def }}+V_{0}^{\text {aut }}$, where $V_{0}^{\text {aut }}$ is the autarky value as defined in (8), and $V_{0}^{\text {def }} \equiv V_{\text {def }}\left(b_{0}\right)$ is the value of defaulting net of the autarky value, given by

$$
\begin{aligned}
V_{d e f}(b) & =\mathbb{E}\left\{-\int_{0}^{\tau} e^{-\rho t} \epsilon \max \{0, b-\hat{b}\} d t+e^{-\rho \tau} V(\theta b)\right\} \\
& =\int_{0}^{\infty} \chi e^{-\chi \tau}\left(-\int_{0}^{\tau} e^{-\rho t} \epsilon \max \{0, b-\hat{b}\} d t+e^{-\rho \tau} V(\theta b)\right) d \tau \\
& =-\frac{\epsilon \max \{0, b-\hat{b}\}}{\rho+\chi}+\frac{\chi}{\rho+\chi} V(\theta b),
\end{aligned}
$$

where in the second equality we use our assumption that $\tau$ is exponentially distributed, and where $V(\cdot)$ is the value function of the government, to be defined later. For future reference, the slope of the default value function is

$$
V_{d e f}^{\prime}(b)=-\frac{\epsilon}{\rho+\chi} \mathbf{1}(b>\hat{b})+\frac{\chi}{\rho+\chi} V^{\prime}(\theta b) \theta,
$$

where $\mathbf{1}(\cdot)$ is the indicator function.

\subsubsection{The general problem}

As mentioned before, at every point in time the government decides optimally whether to default or not, in addition to choosing the primary deficit ratio and the inflation rate. Following a default, and once the government regains access to capital markets, it starts accumulating debt and is confronted again with the choice of defaulting. This is a sequence of recursive optimal stopping problems, as one of the policy instruments is a sequence of stopping times. The solution to this problem will be characterized by an optimal default threshold for the debt ratio, which we denote by $b^{*}$. This threshold defines an "inaction region" of the state space, $\left[0, b^{*}\right)$, in which the government chooses not to default, and a region $\left[b^{*}, \infty\right)$ in which the government defaults. We denote by $T\left(b^{*}\right)$ 
the time to default. The latter is a stopping time with respect to the filtration $\left\{\mathcal{F}_{t}\right\}$, defined as the smallest time $t^{\prime}$ such that $b_{t+t^{\prime}}=b^{*}$, i.e. $T\left(b^{*}\right)=\min \left\{t^{\prime}: b_{t+t^{\prime}}=b^{*}\right\} .{ }^{16}$ The government maximizes social welfare (i.e. it behaves benevolently) under discretion. The value function of the government (net of the exogenous autarky value) at time $t=0$ can then be expressed as

$$
V(b)=\max _{b^{*},\left\{c t, \pi_{t}\right\}} \mathbb{E}_{0}\left\{\int_{0}^{T\left(b^{*}\right)} e^{-\rho t}\left(\log \left(1+c_{t}\right)-\frac{\psi}{2} \pi_{t}^{2}\right) d t+e^{-\rho T\left(b^{*}\right)} V_{d e f}\left(b^{*}\right) \mid b_{0}=b\right\},
$$

subject to the law of motion of the debt ratio, equation (4). The optimal default threshold $b^{*}$ must satisfy the following two conditions,

$$
\begin{aligned}
V\left(b^{*}\right) & =V_{d e f}\left(b^{*}\right), \\
V^{\prime}\left(b^{*}\right) & =V_{d e f}^{\prime}\left(b^{*}\right),
\end{aligned}
$$

where $V_{d e f}\left(b^{*}\right)$ and $V_{d e f}^{\prime}\left(b^{*}\right)$ are given respectively by equations (9) and (10) evaluated at $b=b^{*}$. Equation (12) is the value matching condition and it requires that, at the default threshold, the value of honoring debt repayments equals the value of defaulting. Equation (13) is the smooth pasting condition, and it requires that there is no kink at the optimal default threshold. ${ }^{17}$ Both are standard conditions in optimal stopping problems; see e.g. Dixit and Pindyck (1994), Oksendal and Sulem (2007) and Stokey (2009). These conditions imply that the value function is continuous and continuously differentiable: $V \in C^{1}([0, \infty)){ }^{18}$

The solution of this problem must satisfy the Hamilton-Jacobi-Bellman (HJB) equation,

$$
\rho V(b)=\max _{c, \pi}\left\{\log (1+c)-\frac{\psi}{2} \pi^{2}+\left[\left(\frac{\lambda+\delta}{Q(b)}-\lambda+\sigma^{2}-\mu-\pi\right) b+\frac{c}{Q(b)}\right] V^{\prime}(b)+\frac{(\sigma b)^{2}}{2} V^{\prime \prime}(b)\right\},
$$

$\forall b \in\left[0, b^{*}\right)$, together with the boundary conditions (12) and (13). ${ }^{19}$ The term in squared brackets in (14) is the drift of the state variable (see equation 4). The optimal primary deficit ratio and inflation rate are given by the following first order conditions,

$$
\begin{gathered}
c=\frac{Q(b)}{-V^{\prime}(b)}-1 \equiv c(b), \\
\pi=-\frac{b}{\psi} V^{\prime}(b) \equiv \pi(b) .
\end{gathered}
$$

\footnotetext{
${ }^{16}$ Therefore, the time of default in absolute time is $\hat{t}=t+T\left(b^{*}\right)$, i.e. $T\left(b^{*}\right)=\hat{t}-t$.

${ }^{17}$ To be precise, the smooth pasting condition holds as long as $b^{*} \neq \hat{b}$ as the continuation value $V_{d e f}(b)$ is not differentiable at $\hat{b}$.

${ }^{18}$ In addition to these two boundary conditions, there exists the state constraint $b \geq 0$ introduced above.

${ }^{19}$ Obviously, $\forall b \in\left[b^{*}, \infty\right), V(b)=V_{\text {def }}(b)$.
} 
Therefore, the optimal primary deficit ratio increases with bond prices and decreases with the slope of the value function (in absolute value). The intuition is straightforward. Higher bond prices (equivalently, lower bond yields) make it cheaper for the government to finance primary deficits. Likewise, a steeper value function makes it more costly to increase the debt burden by incurring primary deficits. As regards optimal inflation, the latter increases both with the debt ratio and the slope (in absolute value) of the value function. Intuitively, the higher the debt ratio the larger the reduction in the debt burden that can be achieved through a marginal increase in inflation. Similarly, a steeper value function increases the incentive to use inflation so as to reduce the debt burden.

\subsubsection{The 'no inflation' regime}

So far we have analyzed the decision problem of a benevolent government that cannot make credible commitments about its future fiscal policy (including the possibility of defaulting) and monetary policy. In particular, the inability to commit not to use inflation in the future so as to deflate debt away implies that the government is unable to steer investor's inflation expectations in a way that favors welfare outcomes. While lacking commitment, however, we can think of situations in which the government effectively relinquishes the ability to deflate debt away. Formally, we may consider a monetary regime in which inflation is zero in all states: $\pi(b)=0$, for all $b$. The government's problem is given by (14) with $\pi=0$ replacing the optimal inflation choice, and with boundary conditions given again by (12) and (13).

We may interpret such a 'no inflation' scenario in alternative ways. One can first think of a situation in which the government appoints an independent central banker with a strong, in fact arbitrarily great, distaste for inflation. Even under discretion, such a central banker would always choose $\pi=0$. One problem with this interpretation, though, is that it is unlikely that a government that cannot make credible commitments about monetary policy would appoint a central banker with such extreme preferences towards inflation. ${ }^{20}$

A second, perhaps more plausible interpretation is that the government directly issues bonds denominated in foreign currency. In that case, the possibility of deflating debt away simply disappears, and with it the only benefit of inflating in this model. As a result, optimal inflation is always zero in such a scenario.

Finally, we may think of a situation in which the government joins a monetary union in which the common monetary authority has an extreme distaste for inflation. If the costs of exiting the monetary union are very high, then joining it signals a credible anti-inflationary commitment.

\footnotetext{
${ }^{20}$ In section 5 we will consider a more general scenario in which the government appoints a conservative central banker whose distaste for inflation is greater than that of society, but not so extreme as to imply zero inflation at all times.
} 
In what follows, we will simply refer to this scenario as the 'no inflation regime', keeping in mind that such scenario admits several interpretations along the lines just discussed.

\subsection{Foreign investors}

When choosing fiscal and monetary policy, the government takes as given the mapping between the debt ratio and the nominal price of bonds, $Q(b)$. We now characterize such bond price function. The government sells bonds to competitive risk-neutral foreign investors that can invest elsewhere at the risk-free real rate $\bar{r}$. As explained before, bonds pay a coupon rate $\delta$ and are amortized at rate $\lambda$. Following a default at time $\hat{t}$, and during the exclusion period of the government, investors receive no payments. Once the exclusion/renegotiation period ends (at time $t^{\prime}+\tau$ ), investors recover a fraction $\theta P_{\hat{t}+\tau} Y_{\hat{t}+\tau} /\left(P_{\hat{t}} Y_{\hat{t}}\right)=\theta Y_{\hat{t}+\tau} / Y_{\hat{t}}$ of the nominal value of each bond, where we have used the fact that optimal inflation is zero during the exclusion period, such that $P_{\hat{t}+\tau}=P_{\hat{t}}$. ${ }^{21}$ They also anticipate that the government's debt ratio at the time of reentering financial markets will be $\theta b^{*}$, such that their outstanding bonds will carry a market price $Q\left(\theta b^{*}\right)$. Finally, investors discount future nominal payoffs with the accumulated inflation between the time of the bond purchase and the time such payoffs accrue. Therefore, the nominal price of the bond at time $t=0$ for a current debt ratio $b \leq b^{*}$ is given by

$Q(b)=\mathbb{E}_{0}\left[\int_{0}^{T\left(b^{*}\right)} e^{-(\bar{r}+\lambda) t-\int_{0}^{t} \pi_{s} d s}(\lambda+\delta) d t+e^{-\bar{r}\left[T\left(b^{*}\right)+\tau\right]-\lambda T\left(b^{*}\right)-\int_{0}^{T\left(b^{*}\right)} \pi_{s} d s} \theta \frac{Y_{T\left(b^{*}\right)+\tau}}{Y_{T\left(b^{*}\right)}} Q\left(\theta b^{*}\right) \mid b_{0}=b\right]$,

where again $T\left(b^{*}\right)$ denotes the time to default and $b$ follows the law of motion (4). ${ }^{22}$ Applying the Feynman-Kac formula, we obtain the following recursive representation,

$$
Q(b)(\bar{r}+\pi(b)+\lambda)=(\lambda+\delta)+\left[\left(\frac{\lambda+\delta}{Q(b)}-\lambda+\sigma^{2}-\mu-\pi\right) b+\frac{c(b)}{Q(b)}\right] Q^{\prime}(b)+\frac{(\sigma b)^{2}}{2} Q^{\prime \prime}(b),
$$

for all $b \in\left[0, b^{*}\right)$. To determine the boundary condition for $Q(b)$, we calculate the expected value of outstanding bonds at the time of default $\left(T\left(b^{*}\right)=0\right)$,

$$
\begin{aligned}
Q\left(b^{*}\right) & =\mathbb{E}_{0}\left[e^{-\bar{r} \tau} \theta \frac{Y_{\tau}}{Y_{0}} Q\left(\theta b^{*}\right)\right]=\int_{0}^{\infty} \chi e^{-\chi \tau} \mathbb{E}_{0}\left[e^{-\bar{r} \tau} \theta \frac{Y_{\tau}}{Y_{0}} Q\left(\theta b^{*}\right) \mid \tau\right] d \tau \\
& =\int_{0}^{\infty} \chi e^{-(\bar{r}+\chi-\mu) \tau} \theta Q\left(\theta b^{*}\right) d \tau=\frac{\chi}{\bar{r}+\chi-\mu} \theta Q\left(\theta b^{*}\right),
\end{aligned}
$$

\footnotetext{
${ }^{21}$ The average recovery rate equals $\mathbb{E}\left[\theta Y_{\hat{t}+\tau} / Y_{\hat{t}}\right]=\theta \mathbb{E}_{\tau}\left\{\mathbb{E}_{[}\left[Y_{\hat{t}+\tau} / Y_{\hat{t}} \mid \tau\right]\right\}=\theta \int_{0}^{\infty} \chi e^{-\chi \tau} e^{\mu \tau} d \tau=\theta \chi /(\chi-\mu)$, where we have used $\mathbb{E}\left[Y_{\hat{t}+\tau} / Y_{\hat{t}} \mid \tau\right]=\exp (\mu \tau)$ and the fact that $\tau$ is exponentially distributed.

${ }^{22}$ Notice that the recovery payoff $\theta\left(Y_{T\left(b^{*}\right)+\tau} / Y_{T\left(b^{*}\right)}\right) Q\left(\theta b^{*}\right)$ is discounted by $\exp \left\{-\lambda T\left(b^{*}\right)-\int_{0}^{T\left(b^{*}\right)} \pi_{s} d s\right\}$, as opposed to $\exp \left\{-\lambda\left[T\left(b^{*}\right)+\tau\right]-\int_{0}^{T\left(b^{*}\right)+\tau} \pi_{s} d s\right\}$, because no principal is repaid and no inflation is created during the exclusion period (of length $\tau$ ).
} 
where in the third equality we have used $\mathbb{E}_{0}\left[\frac{Y_{\tau}}{Y_{0}} \mid \tau\right]=e^{\mu \tau}$. The partial differential equation (18), together with the boundary condition (19), provide the risk-neutral pricing of the nominal defaultable sovereign bond. ${ }^{23}$

\subsection{Some definitions}

Given a current bond price $Q(b)$, the implicit bond yield $r(b)$ is the discount rate for which the discounted future promised cash flows from the bond equal its price. The discounted future promised payments are $\int_{0}^{\infty} e^{-(r(b)+\lambda) t}(\lambda+\delta) d t=\frac{\lambda+\delta}{r(b)+\lambda}$. Therefore, the bond yield function is

$$
r(b)=\frac{\lambda+\delta}{Q(b)}-\lambda
$$

The gap between the yield $r(b)$ and the riskless real rate $\bar{r}$ reflects both (a) the risk of sovereign default, i.e. a risk premium, and (b) the anticipation of inflation during the life of the bond, i.e. an inflation premium. In order to disentangle both factors, we define the riskless yield as $\tilde{r}(b)=\frac{\lambda+\delta}{\tilde{Q}(b)}-\lambda$, where $\tilde{Q}(b)$ is the price that the investor would pay for a riskless nominal bond with the same promised cash flows as the risky nominal bond. Appendix B defines $\tilde{Q}(b)$ and explains how to solve for it. We then decompose

$$
r(b)-\bar{r}=(r(b)-\tilde{r}(b))+(\tilde{r}(b)-\bar{r}),
$$

where $r(b)-\tilde{r}(b)$ is the risk premium, and $\tilde{r}(b)-\bar{r}$ is the inflation premium. In the no inflation regime, the riskless rate is simply $\tilde{r}(b)=\bar{r}$, the inflation premium is zero, and the risk premium is $r(b)-\bar{r}$.

Given the definition of the bond yield, the drift function of the state variable can be expressed as

$$
s(b) \equiv\left(r(b)-\pi(b)-\mu+\sigma^{2}\right) b+\frac{c(b)}{Q(b)} .
$$

Notice that an important determinant of the drift is the difference between the nominal bond yield and the instantaneous inflation rate, $r(b)-\pi(b)$. We may refer to the latter as ex-post real interest rate, or simply real interest rate.

Finally, we define the expected time to default, given a current debt ratio $b$, as

$$
T^{e}(b) \equiv \mathbb{E}_{0}\left[T\left(b^{*}\right) \mid b_{0}=b\right]=\mathbb{E}_{0}\left[\int_{0}^{T\left(b^{*}\right)} 1 d t \mid b_{0}=b\right] .
$$

\footnotetext{
${ }^{23}$ Again, there also exists the state constraint $b \geq 0$.
} 
Appendix $\mathrm{C}$ shows how to compute $T^{e}(b)$ numerically.

\subsection{Equilibrium}

We define our equilibrium concept:

Definition $1 A$ Markov Perfect Equilibrium is an interval $\Phi=\left[0, b^{*}\right)$, a value function $V: \Phi \rightarrow$ $\mathbb{R}$, a pair of policy functions $c, \pi: \Phi \rightarrow \mathbb{R}$ and a bond price function $Q: \Phi \rightarrow \mathbb{R}_{+}$such that

1. Given prices $Q$, for any initial debt $b_{0} \in \Phi$ the value function $V$ solves the government problem (14), with boundary conditions (12) and (13); the optimal inflation is $\pi$, the optimal deficit ratio is $c$, and the optimal debt threshold is $b^{*}$.

2. Given the optimal inflation $\pi$, deficit ratio $c$ and the interval $\Phi$, bond prices satisfy the pricing equation (18).

The government takes the bond price as given and chooses inflation and deficit (continuous policies) and default (stopping policy) to maximize its value function. The investors take these policies as given and price government bonds accordingly.

\section{Quantitative analysis}

Having laid out our theoretical model, we now use it in order to analyze the trade-off between price stability and the sustainability of sovereign debt. We are not able to find an analytical solution to our model. Therefore we resort to numerical techniques. We next describe our solution algorithm.

\subsection{Computational algorithm}

Here we propose a computational algorithm aimed at finding the equilibrium. The structure of the model complicates its solution as it comprises a pair of coupled ordinary difference equations (ODEs): the HJB equation (14) and the bond pricing equation (18). The policies obtained from the HJB are necessary to compute the bond prices and simultaneously, bond prices are necessary to compute the drift in the HJB equation.

In order to solve the HJB and bond pricing equations, we employ an upwind finite difference method. ${ }^{24}$ It approximates the value function $V(b)$ and the bond price function $Q(b)$ on a finite grid with steps $\Delta b: b \in\left\{b_{1}, \ldots, b_{I}\right\}$, where $b_{i}=b_{i-1}+\Delta b=b_{1}+(i-1) \Delta b$ for $2 \leq i \leq I$, with

\footnotetext{
${ }^{24}$ Barles and Souganidis (1991) have proved how this method converges to the unique viscosity solution of the problem. The latter is the appropriate concept of a general solution for stochastic optimal control problems (Crandall and Lions, 1983; Crandall, Ishii and Lions, 1992).
} 
bounds $b_{1}=0$ and $b_{I+1}=b^{*} .{ }^{25}$ We use the notation $V_{i}^{(n)} \equiv V^{(n)}\left(b_{i}\right), i=1, \ldots, I$, where $n=0,1,2 \ldots$ is the iteration counter, and analogously for $Q_{i}^{(n)}$.

In order to compute the numerical solution to the recursive competitive equilibrium we proceed in three steps. We consider an initial guess of the bond price function, $Q^{(0)} \equiv\left\{Q_{i}^{(0)}\right\}_{i=1}^{I}$, and the default threshold, $b_{(0)}^{*}$. Set $n=1$. Then:

Step 1: Government problem. Given $Q^{(n-1)}$ and $b_{(n-1)}^{*}$, we solve the optimal stopping problem with variable controls. This means solving the HJB equation (14) in the domain $\left[0, b_{(n-1)}^{*}\right]$ imposing the smooth pasting condition (13) (but not the value matching condition) to obtain an estimate of the value function $V^{(n)} \equiv\left\{V_{i}^{(n)}\right\}_{i=1}^{I}$ and of primary deficit and inflation, $\left(c^{(n)}, \pi^{(n)}\right) \equiv\left\{c_{i}^{(n)}, \pi_{i}^{(n)}\right\}_{i=1}^{I}$.

Step 2: Investors problem. Given $c^{(n)}, \pi^{(n)}$ and $b_{(n-1)}^{*}$, solve the bond pricing equation (18) and obtain $Q^{(n)}$ in the domain $\left[0, b_{(n-1)}^{*}\right]$. Then iterate again on steps 1 and 2 until both the value and bond price functions converge for given $b_{(n-1)}^{*}$.

Step 3: Optimal boundary. Given $V^{(n)}$ from step 2, we check whether the value matching condition (12) is satisfied. We compute $V^{(n)}\left(b_{(n-1)}^{*}\right)=V_{I}^{(n)}$ and $V_{d e f}^{(n)}\left(b_{(n-1)}^{*}\right)=-\frac{\epsilon \max \left\{0, b_{(n-1)}^{*}-\hat{b}\right\}}{\rho+\chi}+$ $\frac{\chi}{\rho+\chi} V_{\theta I}^{(n)}$. If $V^{(n)}\left(b_{(n-1)}^{*}\right)>V_{d e f}^{(n)}\left(b_{(n-1)}^{*}\right)$, then increase the threshold to a new value $b_{(n)}^{*}$. If $V^{(n)}\left(b_{(n-1)}^{*}\right)<V_{d e f}^{(n)}\left(b_{(n-1)}^{*}\right)$, then decrease the threshold. Set $n:=n+1$. Proceed again to steps 1 and 2 until the value matching condition $V\left(b^{*}\right)=V_{d e f}\left(b^{*}\right)$ is satisfied.

Appendix A provides further details on these steps. The idea of the algorithm is to find the equilibrium numerically by moving the default threshold $b^{*}$ and solving the HJB and bond pricing equations. The algorithm stops when the value matching condition (12) is satisfied.

\subsection{Calibration}

Let the unit of time by 1 year, such that all rates are in annual terms. Most papers in the literature on quantitative optimal sovereign default models set the world riskless real interest rate and the subjective discount rate to $1 \%$ and $5 \%$ per quarter, respectively. ${ }^{26}$ We thus set $\bar{r}=0.04$ and $\rho=0.20$ per year.

In order to calibrate the drift and volatility of the exogenous output process, we use annual GDP growth data for the EMU periphery countries (Greece, Italy, Ireland, Portugal, Spain) over

\footnotetext{
${ }^{25}$ We thus have $\Delta b=b^{*} / I$. We use $I=800$ grid points in all our simulations.

${ }^{26}$ The world interest rate is set to $1 \%$ per quarter in Aguiar \& Gopinath (2006), Benjamin and Wright (2009), Hatchondo and Martinez (2009), Yue (2010), Mendoza and Yue (2012) and Chatterjee and Eyigungor (2012). The subjective discount rate is set equal to or close to 5\% per quarter in Arellano (2008), Benjamin and Wright (2009), Hatchondo and Martinez (2009), and Chatterjee and Eyigungor (2012), and in Aguiar \& Gopinath's (2006) model extension with bailouts.
} 
the period 1995-2012. ${ }^{27}$ Averaging the mean and standard deviation of GDP growth across these countries, we obtain $\mu=0.022$ and $\sigma=0.032$.

The bond amortization rate $\lambda$ is such that the average Macaulay bond duration, $1 /(\lambda+\bar{r})$, is 5 years, which is broadly consistent with international evidence on bond duration (see e.g. Cruces et al. 2002). We set the coupon rate $\delta$ equal to $\bar{r}$, such that the price of a riskless real bond, $(\delta+\lambda) /(\bar{r}+\lambda)$, is normalized to 1 .

We set $\chi$ such that the average duration of the exclusion period is $1 / \chi=3$ years, consistently with international evidence on exclusion periods in Dias and Richmond (2007). The bond recovery rate parameter, $\theta$, is set such that the mean recovery rate, $\theta \chi /(\chi-\mu)$, is $60 \%$, consistent with the evidence in Benjamin and Wright (2009) and Cruces and Trebesch (2011).

The parameters determining the output loss during the exclusion period, $\hat{b}$ and $\varepsilon$, are set in order for the model with zero inflation to replicate (i) the average ratio of external public debt over GDP across EMU periphery economies in our sample period (35.6\%) and (ii) an output decline of $6 \%$ following default. ${ }^{28}$ Regarding the latter, the literature offers a broad range of values, from $2 \%$ (Aguiar and Gopinath, 2006) to 13-14\% (Mendoza and Yue, 2012; Arellano, 2008). The midpoint of this range would be $8 \%$. We target a more conservative output loss of $6 \%$.

Finally, in order to calibrate the government's dislike for inflation, $\psi$, we turn to the inflationary model regime and target an average inflation rate of $3.2 \%$. The latter corresponds to the average CPI inflation differential between the EMU periphery economies and the US during the period 1987-1997. ${ }^{29}$ We thus use observed inflation differentials in the years before the creation of EMU in order to back up the preferences for inflation in such countries at a time when they were able to issue debt in their own currency. Table 1 summarizes the calibration.

\footnotetext{
${ }^{27}$ See Appendix E for data sources and treatment.

${ }^{28}$ We use the no-inflation scenario as the model counterpart of our sample region and period (the average EMU peripheral economy in the euro period). First, as discussed in section 2.3.3, the no-inflation regime can be interpreted as an (anti-inflationary) monetary union. Second, as we explain below, we choose the US CPI as the empirical proxy for the 'World price' in the model, which is furthermore normalized to 1 . We thus use CPI inflation differentials (rather than levels) relative to the US as the relevant empirical counterpart for inflation in the model. As we show in section 3.4, the average inflation differential across EMU peripheral economies was close to zero ( $0.4 \%$ annual) in our sample period, such that the no-inflation regime provides a good approximation for observed inflation differentials in our sample.

${ }^{29}$ We thus take the US CPI as the proxy for the 'World price' in the model. Notice also that, since the latter is normalized to 1 , we target inflation differentials as opposed to inflation levels.
} 
Table 1. Baseline calibration

\begin{tabular}{ccll}
\hline \hline Parameter & Value & \multicolumn{1}{c}{ Description } & \multicolumn{1}{c}{ Source/Target } \\
\hline $\bar{r}$ & 0.04 & world real interest rate & standard \\
$\rho$ & 0.20 & subjective discount rate & standard \\
$\mu$ & 0.022 & drift output growth & average growth EMU periphery \\
$\sigma$ & 0.032 & diffusion output growth & growth volatility EMU periphery \\
$\lambda$ & 0.16 & bond amortization rate & Macaulay duration $=5$ years \\
$\delta$ & 0.04 & bond coupon rate & price of riskless real bond $=1$ \\
$\chi$ & 0.33 & reentry rate & mean duration of exclusion $=3$ years \\
$\theta$ & 0.56 & recovery rate parameter & mean recovery rate $=60 \%$ \\
$\epsilon$ & 1.50 & default cost parameter & output loss during exclusion $=6 \%$ \\
$\hat{b}$ & 0.332 & default cost parameter & average external debt/GDP ratio $(35.6 \%)$ \\
$\psi$ & 9.15 & inflation disutility parameter & mean inflation rate (1987-1997) $=3.2 \%$ \\
\hline \hline
\end{tabular}

\subsection{Equilibrium}

Inflationary equilibrium. The green dotted lines in Figure 1 show the equilibrium value function and policy functions in the 'inflationary regime'. As shown by the upper left subplot, the value function declines gently and almost linearly with the country's debt burden, except for debt ratios very close to default when the slope increases sharply. The optimal default threshold equals $b^{*}=37.0 \%$ and is marked by a green circle. At that point, the government defaults. Following the exclusion period, it reenters capital markets with a debt ratio $\theta b^{*}=20.7 \%$.

As regards nominal bond prices, $Q(b)$, their gap with respect to the price of a riskless real bond (normalized to 1) reflects mainly expected inflation during the life of the bond as opposed to default risk, except for debt ratios close to default. This can be seen more clearly in the second line of Figure 2 , which displays how the gap between the nominal yield, $r(b)=(\delta+\lambda) / Q(b)-\lambda$, and the riskless real rate $\bar{r}$ is decomposed between the risk and inflation premia, as defined in section 2.5. Indeed, for all $b$ except those very close to $b^{*}$, bond yields reflect mostly the inflation premium, rather than the risk premium, because default is still perceived as a very distant outcome, as reflected by an expected time-to-default of around 40 years. It is only as debt approaches the default threshold that investors start perceiving default as rather imminent, demanding higher and higher risk premia, which leads to the collapse of bond prices to their boundary value $\left(Q\left(b^{*}\right)=0.44\right)$.

The value function and bond prices, together with the state $b$, determine in turn the policy functions for inflation and primary deficit, as described in equations (15) and (16). Regarding 

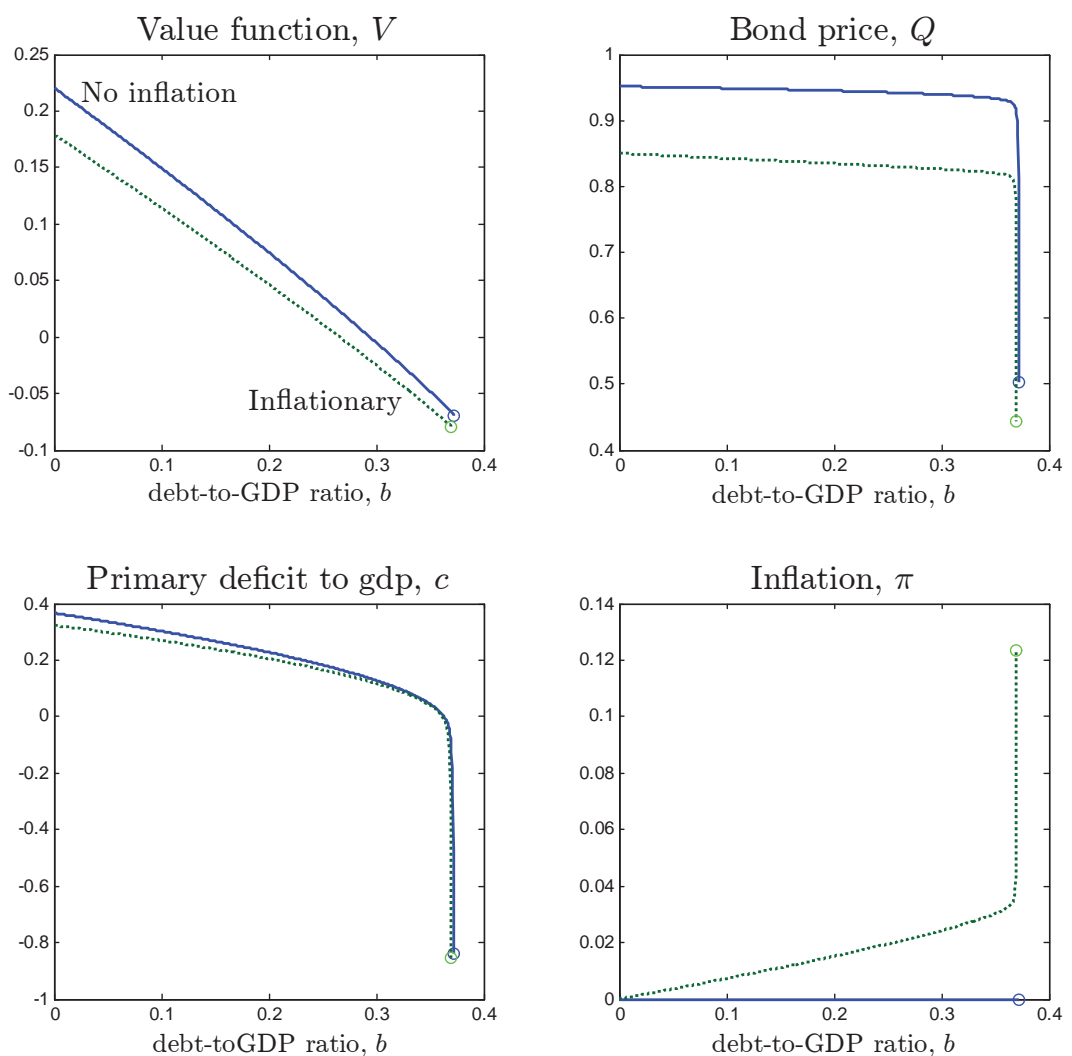

Figure 1: Equilibrium value function, bond price and policy functions. 

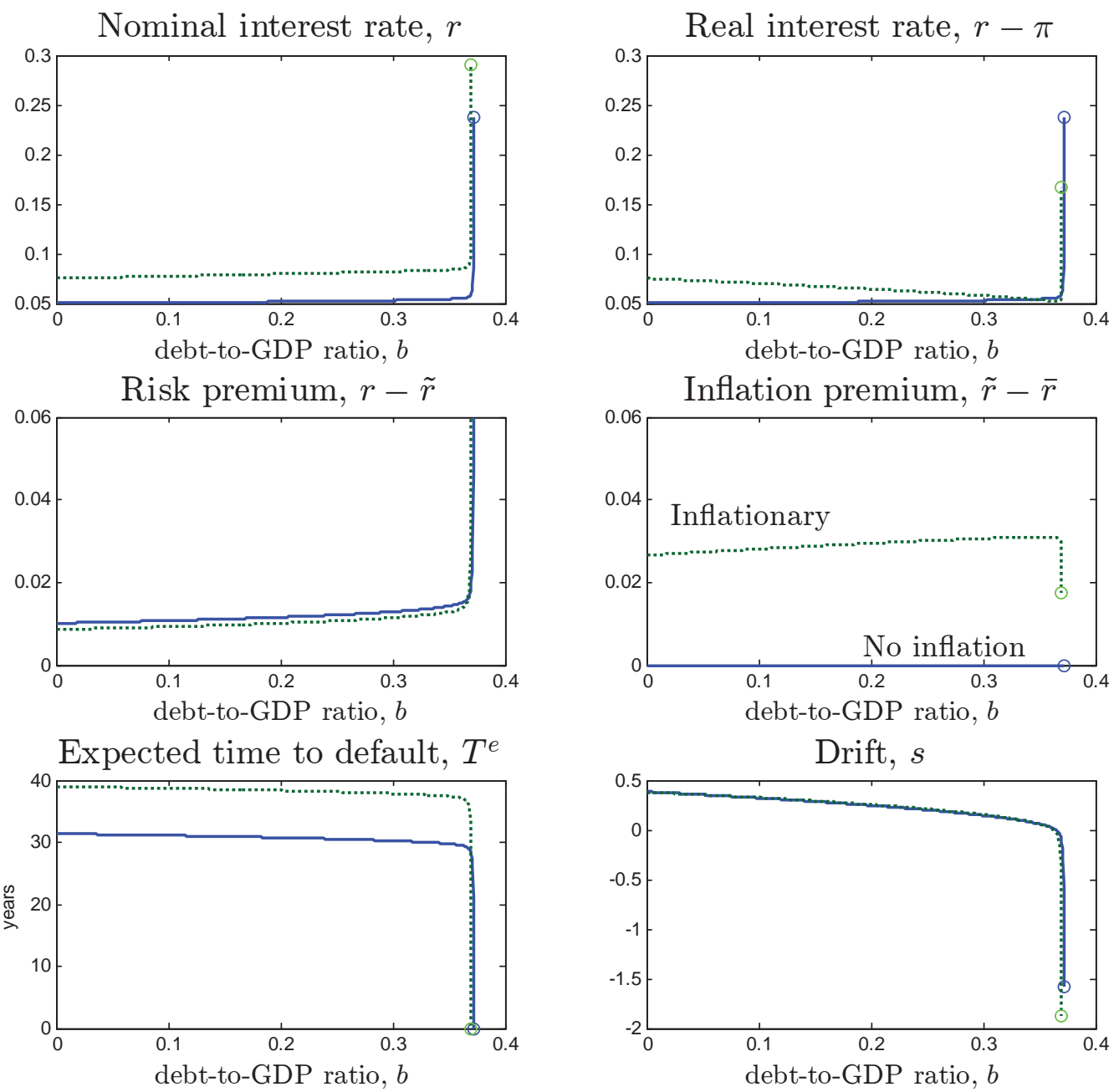

Figure 2: Equilibrium interest rates, risk and inflation premia, expected time to default and drift. 
inflation, the government's incentive to deflate debt away increase approximately linearly with the debt ratio. This is because the value function is approximately linear, such that the welfare gain per unit of debt reduction is roughly constant. However, in the vicinity of the default threshold, the value function starts declining more and more steeply, such that a marginal reduction in the debt ratio yields a higher and higher marginal gain in welfare. ${ }^{30}$ As a result, optimal inflation increases steeply until reaching about $12 \%$ at the default threshold. Therefore, under discretion, the optimal trade-off between price stability and sovereign debt sustainability prescribes a roughly linear increase in inflation for moderate debt levels, and a strong increase as the economy approaches default.

Finally, the primary deficit ratio declines too in an almost linear fashion, reflecting the gentle decline in bond prices and the nearly constant slope of the value function. As debt approaches the default threshold, however, the sharp decline in bond prices leads the government to drastically reduce its primary deficit, which actually turns to surplus once the economy gets sufficiently close to default.

No-inflation equilibrium. Consider now the equilibrium in the 'no-inflation regime', depicted by the solid blue lines in Figure 1. As explained in section 2.3.3, this scenario can be interpreted as issuing foreign currency debt or joining a monetary union with a very strong anti-inflationary commitment. Notice first that the optimal default threshold ( $b_{\pi=0}^{*}=37.2 \%$; see blue circles) is essentially the same as in the baseline, inflationary regime. This means that the equilibrium range of debt ratios is basically the same in both regimes. The first subplot of Figure 1 reveals our first main result: the value function is higher under no inflation for any debt ratio, even when the economy is close to default. A first and obvious reason is that the no inflation regime avoids the direct welfare costs of inflation $(\psi / 2) \pi^{2}$. A second reason is the following. As shown in Figure 2 , the no inflation regime reduces bond yields $r$ (i.e. it lowers bond prices) by eliminating the inflation premium. Lower bond prices lead the government to choose (slightly) higher primary deficits, which allows for higher consumption given the exogenous output flow.

Notice that the no inflation regime raises risk premia vis-à-vis the inflationary regime. This reflects the fact that default becomes more likely when the government gives up the ability to use inflation so as to stabilize its debt. However, quantitatively the increase in risk premia is very small, which together with the absence of inflation premia produces the reduction in bond yields discussed above. The reason for such a small increase in risk premia is that, for all debt ratios except those very close to $b^{*}$, default is still perceived as rather distant, as reflected by an expected time to default of about 30 years. As a result, the fact investors expect default to happen somewhat sooner than in the inflationary regime (by about 8 years) is not enough to raise risk

\footnotetext{
${ }^{30}$ The increase in the slope (in absolute value) of the value function is hard to appreciate in Figure 1, because it only takes place at debt ratios very close to $b^{*}$. Zooming in the $V(b)$ plot in the neighborhood of $b^{*}$ reveals clearly such increase in the slope. The latter plot is available upon request.
} 
premia significantly.

In order to gain further understanding of why social welfare is higher under zero inflation for any debt ratio, we decompose the value function into two components: $V(b)=V_{c}(b)+V_{\pi}(b)$, where $V_{c}(b)$ and $V_{\pi}(b)$ capture the contribution of consumption utility and inflation disutility, respectively, to overall welfare (net of the autarky value). Notice that consumption utility (net of exogenous (log)output) equals $\log (1+c(b))$ when the country is in good credit and $-\epsilon \max \{0, b-\hat{b}\}$ while in exclusion. Likewise, inflation disutility equals $-\psi \pi(b)^{2} / 2$ while in good credit and zero during exclusion. We thus have

$$
\begin{gathered}
\rho V_{c}(b)=\log (1+c(b))+\left[\left(r(b)-\pi(b)-\mu+\sigma^{2}\right) b+\frac{c}{Q(b)}\right] V_{c}^{\prime}(b)+\frac{(\sigma b)^{2}}{2} V_{c}^{\prime \prime}(b), \\
\rho V_{\pi}(b)=-\frac{\psi}{2} \pi(b)^{2}+\left[\left(r(b)-\pi(b)-\mu+\sigma^{2}\right) b+\frac{c}{Q(b)}\right] V_{\pi}^{\prime}(b)+\frac{(\sigma b)^{2}}{2} V_{\pi}^{\prime \prime}(b),
\end{gathered}
$$

for $b<b^{*}$, with respective boundary conditions

$$
V_{c}\left(b^{*}\right)=-\frac{\epsilon \max \left\{0, b^{*}-\hat{b}\right\}}{\rho+\chi}+\frac{\chi}{\rho+\chi} V_{c}\left(\theta b^{*}\right), \quad V_{\pi}\left(b^{*}\right)=\frac{\chi}{\rho+\chi} V_{\pi}\left(\theta b^{*}\right)
$$

Both value functions can be solved using numerical methods similar to those described in Appendix A. ${ }^{31}$ Figure 3 shows the contribution of each component to overall welfare in each monetary regime. The reduction in inflation disutility from giving up debt deflation is relatively large and increases slightly with the debt ratio. As regards consumption utility, it contributes positively to the welfare gap between the no-inflation and the inflationary regime at relatively low debt ratios, and negatively in the vicinity of the default threshold. The reason is that, as the economy approaches default, the ex-post real interest rate $r(b)-\pi(b)$ increases under no inflation but decreases in the inflationary regime, as shown in Figure 2. Ceteris paribus, this permits a lower drift and hence a slower debt accumulation in the latter regime, which favors debt sustainability. Notice however that, even when debt is close to $b^{*}$, the contribution of consumption utility is relatively similar in both regimes. This is because, in the inflationary regime, the reduction in real interest rates mentioned before is very weak, as the increase in instantaneous inflation is largely compensated by the increase in nominal yields.

Figure 3 also reveals the following: the fact that the value function at the default threshold is higher under no inflation is due entirely to the expected stream of inflation disutility flows at that

\footnotetext{
${ }^{31}$ Notice that, since we have already solved for the optimal default threshold $b^{*}$, we do not need to impose smooth pasting conditions in order to solve for $V_{c}(b)$ and $V_{\pi}(b)$.
} 

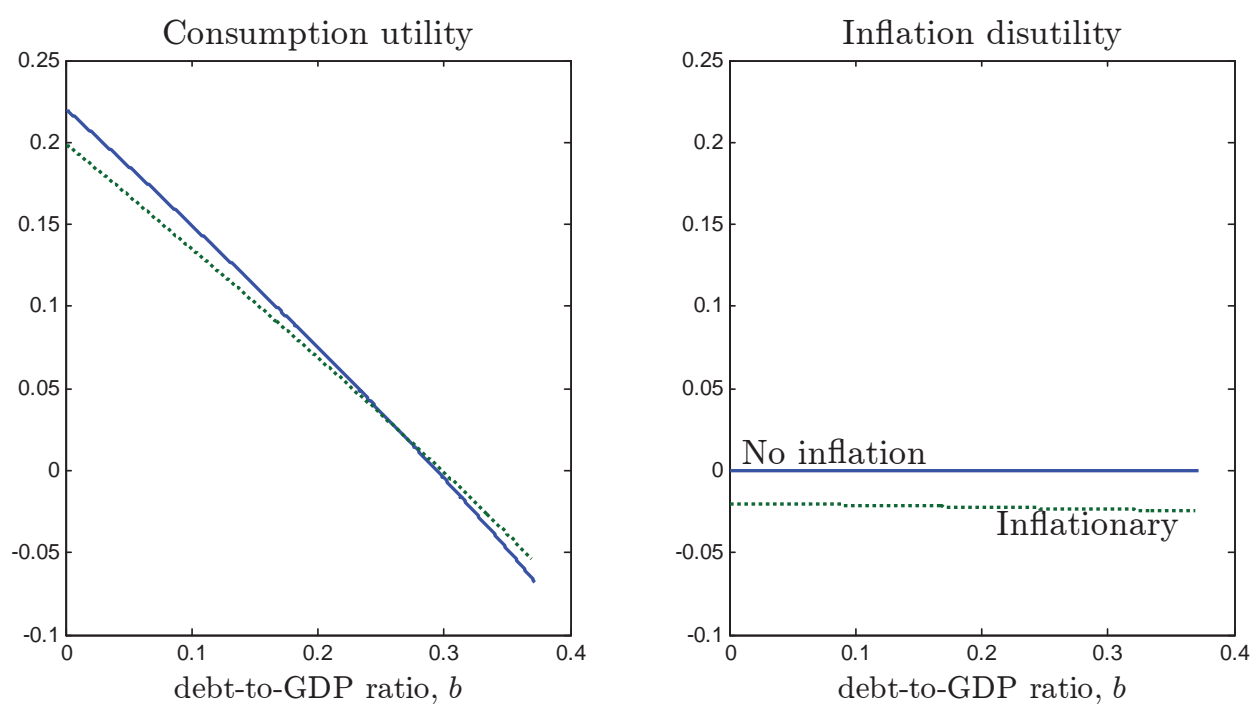

Figure 3: Welfare decomposition

point, $V_{\pi}\left(b^{*}\right)$. In both monetary regimes, the value function at default equals

$$
V\left(b^{*}\right)=V_{d e f}\left(b^{*}\right)=-\frac{\epsilon \max \left\{0, b^{*}-\hat{b}\right\}}{\rho+\chi}+\frac{\chi}{\rho+\chi} V\left(\theta b^{*}\right),
$$

which is precisely the sum of the two terminal values in $(22)$. The fact that $b^{*}$ is very similar in both cases implies that so is the output loss from default, $\epsilon \max \left\{0, b^{*}-\hat{b}\right\}$, as is the debt ratio at which the government reenters capital markets following the exclusion period $\left(\theta b^{*}=20.7 \%\right.$, versus $\left.\theta b_{\pi=0}^{*}=20.8 \%\right) .{ }^{32}$ However, at such reentry ratio the value function is higher in the no-inflation regime, precisely because it avoids the welfare costs of inflation.

To summarize the previous discussion, the no-inflation regime achieves superior welfare outcomes at any debt ratio. It does so by avoiding the temptation to inflate at points of the state space where default is still perceived as rather distant, and hence where the stabilizing benefits from deflating debt away are relatively minor. Even at debt ratios relatively close to default, the gains from deflating debt away discretionarily are rather small, as the beneficial effects of higher inflation on debt sustainability are mostly undone by the increase in nominal yields that goes hand in hand with higher inflation expectations.

\footnotetext{
${ }^{32}$ Notice that $b^{*}>\hat{b}=0.332$ in both regimes. Thus, the loss in $(\log )$ output from default equals $\epsilon\left(b^{*}-\hat{b}\right)$ in both cases.
} 


\subsection{Average performance}

So far we have analyzed the equilibrium value function and policy functions, i.e. the optimal choices of fiscal and monetary policy and the associated welfare at each point of the state space. The main result from the previous section is that the no-inflation regime yields higher welfare at any debt ratio, including at the respective default thresholds. This does not guarantee however that average welfare would be higher too. Since value functions are monotonically decreasing in both regimes, if the inflationary regime delivered sufficiently lower debt ratios most of the time, it could also achieve higher average welfare.

In order to compute unconditional averages of welfare and other variables, we thus need to solve for the stationary distribution of the state variable, the debt ratio. For this purpose, it is useful to distinguish between (a) 'normal' times in which the country is in good credit standing and (b) the exclusion periods that follow each default. The stationary distribution conditional on being in 'normal' times, which we may denote by $f(b)$, satisfies the following Kolmogorov Forward Equation (KFE),

$$
\begin{aligned}
0= & -\frac{d}{d b}\left\{\left[\left(\frac{\lambda+\delta}{Q(b)}+\sigma^{2}-\mu-\lambda-\pi(b)\right) b+\frac{c(b)}{Q(b)}\right] f(b)\right\}+\frac{1}{2} \frac{d^{2}}{d b^{2}}\left[(\sigma b)^{2} f(b)\right] \\
& +\chi h \delta\left(b-\theta b^{*}\right)-\chi h \delta\left(b-b^{*}\right),
\end{aligned}
$$

with the constraint $1=\int_{0}^{b^{*}} f(b) d b$. In equation (23), the term $\chi h \delta\left(b-\theta b^{*}\right)$ reflects the fact that, following an exclusion spell, the government reenters the capital market at a debt ratio $b=\theta b^{*}$, where $\delta(\cdot)$ is the Dirac 'delta' and $h$ is a function of the average time spent in exclusion. Likewise, $\chi h \delta\left(b-b^{*}\right)$ captures the fact that at $b=b^{*}$ the government defaults and hence exits the conditional distribution $f(b)$. Appendix D provides further details on how to obtain equation (23) and shows how to compute $f(b)$ numerically, using an upwind finite difference scheme similar to the one employed to solve for the value and bond price functions. Figure 4 displays the stationary distributions of the debt ratio for both the baseline and the no-inflation regimes, conditional on being in normal times. In the baseline regime, the possibility of using inflation to deflate debt away allows the government to shift the debt distribution slightly to the left vis-à-vis the no-inflation regime.

Conditional on being in an exclusion period, we have already seen that primary deficit and inflation are both zero, $c_{t}=\pi_{t}=0$. Since the rate at which the country reenters capital markets is constant at $\chi$ and hence independent of the time elapsed since default, we have that the value function and bond price are equal to their boundary values: $V_{t}=V\left(b^{*}\right)=V_{\text {def }}\left(b^{*}\right), Q_{t}=Q\left(b^{*}\right)$. Finally, we assume for simplicity that during the exclusion period the debt ratio is equal to $b^{*}$, i.e. 


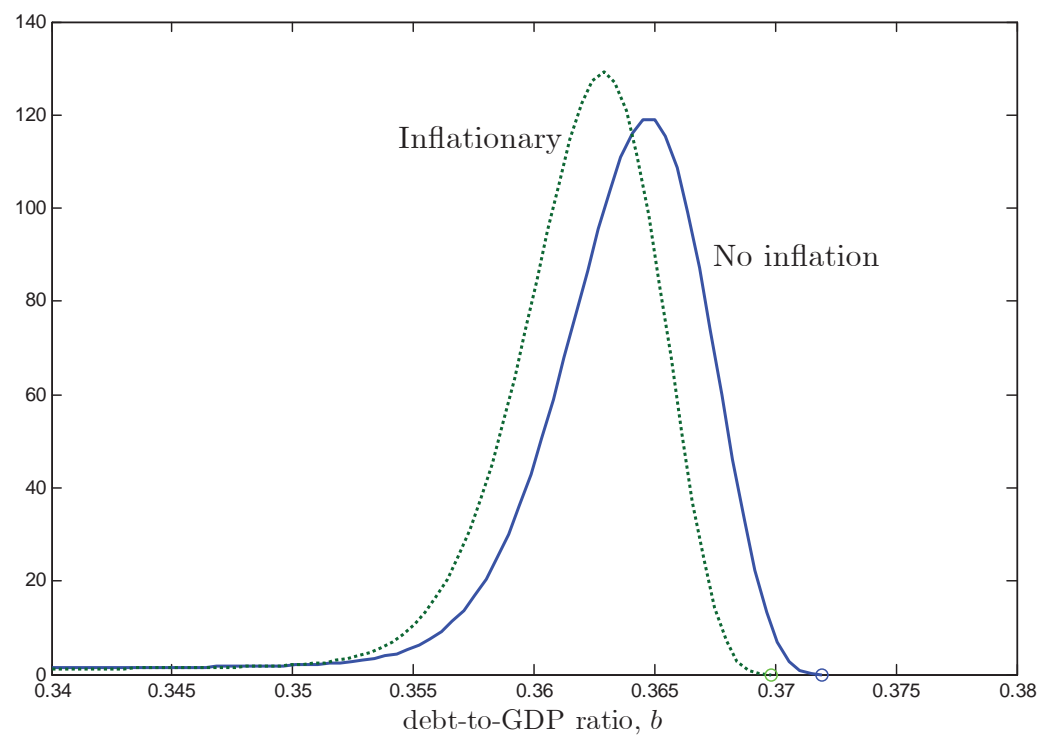

Figure 4: Stationary distribution of debt ratio, $f(b)$

the ratio at which the country defaults. ${ }^{33}$

We can now compute the unconditional mean of each variable as the weighted average of the conditional means, using as weights the average time spent in normal and exclusion periods. It is relatively straightforward to show that the stationary probability of being in normal times and in exclusion periods equal $\mathbb{P}\left[b_{t}<b^{*}\right]=\frac{T^{e}\left(\theta b^{*}\right)}{1 / \chi+T^{e}\left(\theta b^{*}\right)}$ and $\mathbb{P}\left[b_{t}=b^{*}\right]=\frac{1 / \chi}{1 / \chi+T^{e}\left(\theta b^{*}\right)}$, respectively. Thus, the unconditional mean of a variable $x_{t}$ equals

$$
\begin{aligned}
\mathbb{E}\left[x_{t}\right] & =\mathbb{P}\left[b_{t}<b^{*}\right] \mathbb{E}\left[x_{t} \mid b_{t}<b^{*}\right]+\mathbb{P}\left[b_{t}=b^{*}\right] x^{*} \\
& =\frac{T^{e}\left(\theta b^{*}\right)}{1 / \chi+T^{e}\left(\theta b^{*}\right)} \int_{0}^{b^{*}} x(b) f(b) d b+\frac{1 / \chi}{1 / \chi+T^{e}\left(\theta b^{*}\right)} x^{*},
\end{aligned}
$$

where $x^{*}$ is the value of $x_{t}$ during the exclusion period. ${ }^{34}$

Table 2 displays average values of key model variables for both monetary regimes, as well as their corresponding empirical counterparts across EMU periphery countries. ${ }^{35}$ Notice first that,

\footnotetext{
${ }^{33}$ We are thus assuming that during the exclusion/renegotiation period nominal debt outstanding is adjusted at each point in time to changes in the output endowment, such that the debt ratio is kept constant at $b^{*}$. We could alternatively assume that, during the exclusion period, nominal debt outstanding is kept constant at its value at the time of default $\left(B_{\hat{t}}^{*}\right)$, such that the debt ratio changes with the output endowment. This would complicate the analysis while barely affecting the numerical results, given the relatively short average duration of the exclusion period.

${ }^{34}$ As explained above, $c^{*}=0, \pi^{*}=0, V^{*}=V\left(b^{*}\right)$, and $Q^{*}=Q\left(b^{*}\right)$.

${ }^{35}$ All data are annual except bond yields and risk premia which are quarterly and annualized. We stop the sample for yields and risk premia in 2012:Q2 (included) in order to isolate our analysis from the effects of the annoucement
} 
remarkably, the model with no inflation replicates almost exactly the average bond risk premium (154 bp) conditional on being in good credit standing $\left(b<b^{*}\right)$. In the inflationary regime, average bond yields (net of $\bar{r}=400 \mathrm{bp}$ ) while still in the market equal $446 \mathrm{bp}$, which reflects mostly average inflation premia (309 bp) rather than average risk premia (137 bp). They are also significantly higher than average yields under no inflation.

Table 2. Averages values

\begin{tabular}{lcccccc}
\hline \hline & & Data & \multicolumn{4}{c}{ Model } \\
& & $1995-2012$ & \multicolumn{2}{c}{ No inflation } & \multicolumn{2}{c}{ Inflationary } \\
& units & & $b<b^{*}$ & uncond. & $b<b^{*}$ & uncond. \\
\hline debt-to-GDP, $b$ & $\%$ & 35.6 & 35.6 & 35.8 & 35.6 & 35.7 \\
primary deficit ratio, $c$ & $\%$ & 4.1 & 0.5 & 0.5 & 0.4 & 0.4 \\
inflation, $\pi$ & $\%$ & 0.4 & 0 & 0 & 3.2 & 2.9 \\
bond yields $($ net of $\bar{r}), r-\bar{r}$ & bp & 187 & 153 & 315 & 446 & 596 \\
risk premium, $r-\tilde{r}$ & bp & 154 & 153 & 315 & 137 & 297 \\
inflation premium,,$\tilde{r}-\bar{r}$ & bp & 33 & 0 & 0 & 309 & 299 \\
Exp. time to default, $T^{e}$ & years & - & 29.5 & - & 37.1 & - \\
Welfare loss, $V-V_{\pi=0}$ & $\%$ cons. & - & 0 & 0 & -0.27 & -0.26 \\
\hline \hline
\end{tabular}

Note: Data from IMF, national accounts, and Bloomberg. All data are annual except bond yields and risk premia which are quarterly (annualized) and run through 2012:Q2. See Data Appendix for details. The German 10 -year bond yield is used as empirical proxy for the riskless bond yield, $\tilde{r}$. The column labelled ' $b<b^{*}$, displays results conditional on not being in exclusion, the column labelled 'uncond.' displays fully unconditional results. Welfare losses are relative to the no-inflation regime and are expressed in $\%$ of permanent consumption.

Interestingly, the fact that the no-inflation regime delivers lower average yields than the inflationary regime rationalizes the observed reduction in average sovereign yields across the EMU periphery brought about by the creation of the eurozone, if one interprets both regimes as the model counterparts of the EMU and pre-EMU periods respectively. Indeed, average yields on 10-year peripheral bonds decreased from $12.84 \%$ in the period $1987-94$ to $5.87 \%$ in $1995-2012 .{ }^{36}$ Viewed through the lens of our model, this suggests that, when these countries decided to renounce the ability to deflate their debts by joining EMU, the reduction in inflation expectations was a more important factor in investors' pricing of the new euro-denominated bonds than the presumable increase in default risk.

From a welfare perspective, we find that average welfare is lower in the inflationary regime, by the European Central Bank of the Outright Monetary Transactions (OMT) programme in the summer of 2012.

${ }^{36}$ Notice that $r=5.87 \%=(r-\tilde{r})+(\tilde{r}-\bar{r})+\bar{r}=1.54 \%+0.33 \%+4 \%$. 
i.e. when the government deflates away its debt at discretion. The average welfare losses vis$\grave{a}$-vis the no-inflation regime are equivalent to a reduction in permanent consumption of almost $0.3 \%$. Therefore, the leftward shift in the debt distribution shown in Figure 4 is not sufficient to compensate for the fact that the value function is lower at any debt ratio. Such a small shift in the debt distribution reflects the low effectiveness of discretionary debt deflation policies in our framework. Notice that optimal instantaneous inflation is relatively high in the range where the debt distribution accumulates more density, i.e. for $b>0.35 .{ }^{37}$ However, this is largely undone by the increase in nominal yields that goes along with higher inflation expectations. As a result, in the relevant debt range the inflationary regime achieves only marginally lower real interest rates, and hence only marginally slower debt accumulation, relative to the no inflation regime.

\section{Robustness}

We now evaluate the robustness of our main results to alternative calibrations. We will focus on five structural parameters: (i) the amortization rate $\lambda$, (ii) the bond recovery parameter $\theta$, (iii) the default cost parameter $\hat{b}$, (iv) the scale parameter of inflation disutility $\psi$, and (v) the reentry rate into capital markets, $\chi$.

Bond duration. The amortization rate $\lambda$ determines the average Macaulay bond duration, $1 /(\lambda+\bar{r})$, for given riskless real return $\bar{r}$. Table 3 displays averages of a number of key variables for bond durations of 3 and 7 years, both for the no-inflation and the baseline inflationary regimes. For comparison, it also displays the same statistics for the benchmark calibration, with a 5-year bond duration. We find that average welfare continues to be higher in the no-inflation regime. The welfare loss from using discretionary inflation decreases with bond duration. Intuitively, longer bond durations give more stability to the debt ratio, thus reducing the need to use debt deflation. This allows to reduce inflation premia in bond yields and direct utility costs, and hence the welfare loss relative to the no-inflation case.

Bond recovery rate. The bond recovery parameter, $\theta$, controls the average bond recovery rate after default, $\theta \chi /(\chi-\mu)$, for given reentry and trend growth rates $(\chi, \mu)$. Table 3 displays results for average recovery rates of $50 \%$ and $70 \%$ (the benchmark calibration is $60 \%$ ). Again, average welfare is higher if the government renounces the possibility to deflate debt away. In this case, the welfare gains are fairly similar across different calibrations. As in the baseline calibration, the reduction in average inflation premia from giving up debt deflation clearly dominates the increase in average risk premia.

Output loss from default. Parameter $\hat{b}$ controls the loss in (log-)output following default, $\epsilon \max \left\{0, b^{*}-\hat{b}\right\}$, for given scale parameter $\epsilon$ and equilibrium default threshold $b^{*}$. We consider

\footnotetext{
${ }^{37}$ As shown in Figure 1, for $b>0.35$ inflation is above $3 \%$, with a maximum of around $12 \%$ in the limit as $b \rightarrow b^{*}$.
} 
values of $\hat{b}$ such that, in equilibrium, output declines by $3.5 \%$ and $7 \%$ upon default (compared to the benchmark $6 \%$ loss). In this case, the welfare gains from not deflating debt away, while positive, seem more sensitive to the size of output losses associated to default. The reason is the following. In our model, a positive relationship exists between $\hat{b}$ and average debt ratios. Therefore, higher values of $\hat{b}$ imply higher debt on average and therefore a stronger incentive to deflate the latter away. Higher average inflation in turn raises inflation premia and direct utility costs, thus increasing the welfare gap with respect to the no-inflation scenario.

Inflation disutility-average inflation. In our baseline calibration exercise, we set the scale parameter of inflation disutility, $\psi$, in order for the inflationary model regime to replicate the inflation record in our target economies (see section 3.2). This delivered a baseline value of $\psi=9.15$, which produced an average inflation of $3.2 \%$ conditional on being in good credit standing, and $2.9 \%$ including exclusion spells. We now consider values of $\psi$ that deliver average inflation rates of $2 \%$ and $4 \%$. We find that renouncing debt deflation continues to dominate in welfare terms, with the welfare gap decreasing with the scale of inflation disutility. Intuitively, higher inflation costs lowers the incentive to deflate debt in the inflationary regime, thus reducing the direct welfare costs and the increase in nominal yields associated to the latter regime.

Duration of exclusion period. The reentry rate $\chi$ determines the average duration of the exclusion periods following default, $1 / \chi$, set to 3 years in our benchmark calibration. We study the effects of considering average durations of 2 and 5 years. In addition, we consider the relatively extreme case of a 40-year duration, which approximates the case of a permanent autarky following default. Table 3 reveals that our benchmark results remain mostly unchanged, even for quasipermanent exclusion from capital markets. As we saw in the previous section, the welfare gap between both monetary regimes depends not so much on what happens in exclusion (during which output losses are fairly similar and inflation is zero in both cases), but on what happens while in good credit standing. As a result, changes in duration of the exclusion period do not significantly alter the welfare gap between both regimes. 
Table 3. Robustness analysis

\begin{tabular}{|c|c|c|c|c|c|c|c|}
\hline & $\begin{array}{l}\text { Welfare } \\
\% \text { cons. }\end{array}$ & $\begin{array}{c}\text { Prim. deficit } \\
\text { ratio, } \%\end{array}$ & $\begin{array}{c}\text { Inflation } \\
\%\end{array}$ & $\begin{array}{l}\text { Nominal yield } \\
\text { net of } \bar{r}, \mathrm{bp}\end{array}$ & $\begin{array}{c}\text { Risk } \\
\text { prem., bp }\end{array}$ & $\begin{array}{l}\text { Inflation } \\
\text { prem., bp }\end{array}$ & $\begin{array}{l}\text { Exp. time to } \\
\text { default, years }\end{array}$ \\
\hline \multicolumn{8}{|c|}{ I } \\
\hline No inflation & 0 & 0.5 & 0 & 153 & 153 & 0 & 29.5 \\
\hline Inflationary & -0.26 & 0.4 & 2.9 & 446 & 137 & 309 & 37.1 \\
\hline Difference & 0.26 & 0.1 & -2.9 & -294 & 16 & -309 & -7.7 \\
\hline \multicolumn{8}{|c|}{ Average bond duration $=3$ years } \\
\hline No inflation & 0.08 & 0.2 & 0 & 111 & 111 & 0 & 40.4 \\
\hline Inflationary & -0.35 & 0.2 & 3.3 & 448 & 106 & 342 & 47.4 \\
\hline Difference & 0.43 & 0.0 & -3.3 & -336 & 6 & -342 & -6.9 \\
\hline \multicolumn{8}{|c|}{ Average bond duration $=7$ years } \\
\hline No inflation & -0.01 & 0.6 & 0 & 173 & 173 & 0 & 26.0 \\
\hline Inflationary & -0.16 & 0.5 & 2.7 & 433 & 148 & 286 & 34.7 \\
\hline Difference & 0.15 & 0.1 & -2.7 & -260 & 25 & -286 & -8.7 \\
\hline \multicolumn{8}{|c|}{ Bond recovery rate $=50 \%$} \\
\hline No inflation & -0.05 & 0.6 & 0 & 174 & 174 & 0 & 30.8 \\
\hline Inflationary & -0.30 & 0.5 & 3.0 & 466 & 154 & 312 & 38.6 \\
\hline Difference & 0.25 & 0.1 & -3.0 & -292 & 20 & -312 & -7.9 \\
\hline \multicolumn{8}{|c|}{ Bond recovery rate $=70 \%$} \\
\hline No inflation & 0.06 & 0.3 & 0 & 129 & 129 & 0 & 28.3 \\
\hline Inflationary & -0.22 & 0.2 & 2.9 & 425 & 118 & 307 & 35.8 \\
\hline Difference & 0.27 & 0.1 & -2.9 & -296 & 11 & -307 & -7.5 \\
\hline \multicolumn{8}{|c|}{ Default costs $=3.5 \%$ of GDP } \\
\hline No inflation & 0.48 & 0.6 & 0 & 152 & 152 & 0 & 29.8 \\
\hline Inflationary & 0.38 & 0.5 & 1.8 & 329 & 142 & 187 & 34.5 \\
\hline Difference & 0.09 & 0.1 & -1.8 & -176 & 11 & -187 & -4.7 \\
\hline \multicolumn{8}{|c|}{ Default costs $=7 \%$ of GDP } \\
\hline No inflation & -0.19 & 0.4 & 0 & 152 & 152 & 0 & 29.6 \\
\hline Inflationary & -0.54 & 0.3 & 3.4 & 491 & 135 & 356 & 38.4 \\
\hline Difference & 0.35 & 0.1 & -3.4 & -339 & 17 & -356 & -8.8 \\
\hline
\end{tabular}

Note: Welfare is calculated with respect to the no-inflation scenario under the benchmark calibration, and it is expressed in $\%$ of permanent consumption. Average values are unconditional for welfare, deficit and inflation; for all other variables, averages are conditional on not being in exclusion $\left(b<b^{*}\right)$. Benchmark calibration: average 
Table 3 (cont'd). Robustness analysis

\begin{tabular}{|c|c|c|c|c|c|c|c|}
\hline & $\begin{array}{l}\text { Welfare } \\
\% \text { cons. }\end{array}$ & $\begin{array}{c}\text { Prim. deficit } \\
\text { ratio, } \%\end{array}$ & $\begin{array}{c}\text { Inflation } \\
\%\end{array}$ & $\begin{array}{c}\text { Nominal yield } \\
\text { net of } \bar{r}, \mathrm{bp}\end{array}$ & $\begin{array}{c}\text { Risk } \\
\text { prem., bp }\end{array}$ & $\begin{array}{l}\text { Inflation } \\
\text { prem., bp }\end{array}$ & $\begin{array}{l}\text { Exp. Time to } \\
\text { default, years }\end{array}$ \\
\hline \multicolumn{8}{|c|}{ Scale inflation disutility $\psi=6.40$ (average inflation $=4 \%$ ) } \\
\hline No inflation & 0 & 0.5 & 0 & 153 & 153 & 0 & 29.5 \\
\hline Inflationary & -0.34 & 0.4 & 4.0 & 551 & 133 & 419 & 40.0 \\
\hline Difference & 0.34 & 0.1 & -4.0 & -398 & 20 & -419 & -10.6 \\
\hline \multicolumn{8}{|c|}{ Scale inflation disutility $\psi=13.99($ average inflation $=2 \%)$} \\
\hline No inflation & 0 & 0.5 & 0 & 153 & 153 & 0 & 29.5 \\
\hline Inflationary & -0.18 & 0.4 & 2.0 & 352 & 142 & 210 & 34.6 \\
\hline Difference & 0.18 & 0.1 & -2.0 & -199 & 11 & -210 & -5.1 \\
\hline \multicolumn{8}{|c|}{ Average duration of exclusion period $=2$ years } \\
\hline No inflation & -0.11 & 0.5 & 0 & 181 & 181 & 0 & 23.6 \\
\hline Inflationary & -0.36 & 0.4 & 3.0 & 477 & 160 & 316 & 29.6 \\
\hline Difference & 0.25 & 0.1 & -3.0 & -296 & 20 & -316 & -6.0 \\
\hline \multicolumn{8}{|c|}{ Average duration of exclusion period $=5$ years } \\
\hline No inflation & 0.09 & 0.4 & 0 & 127 & 127 & 0 & 39.0 \\
\hline Inflationary & -0.18 & 0.3 & 2.8 & 420 & 116 & 304 & 49.2 \\
\hline Difference & 0.27 & 0.1 & -2.8 & -293 & 11 & -304 & -10.2 \\
\hline \multicolumn{8}{|c|}{ Average duration of exclusion period $=40$ years } \\
\hline No inflation & 0.12 & 0.6 & 0 & 126 & 126 & 0 & 74.3 \\
\hline Inflationary & -0.13 & 0.5 & 2.1 & 409 & 115 & 294 & 93.2 \\
\hline Difference & 0.25 & 0.1 & -2.1 & -283 & 12 & -294 & -19.0 \\
\hline
\end{tabular}

Note: Welfare is calculated with respect to the no-inflation scenario under the benchmark calibration, and it is expressed in $\%$ of permanent consumption. Average values are unconditional for welfare, deficit and inflation; for all other variables, averages are conditional on not being in exclusion $\left(b<b^{*}\right)$. Benchmark calibration: scale inflation disutility $\psi=9.15$, average duration of exclusion period $=3$ years

Importantly, as in the case of the baseline calibration, the welfare gap between the no-inflation and inflationary regimes takes place not only on average, but also state by state. Appendix F displays the value functions in both regimes for each of the calibrations considered in Table 3 . As we show there, both value functions never cross for any of the cases considered. 


\section{Monetary policy delegation}

So far we have compared two alternative scenarios. In the baseline inflationary regime, a benevolent government maximizes social welfare taking into account households' preferences towards inflation, where such preferences are calibrated to match the observed inflation performance in the EMU peripheral economies in the pre-EMU period. In the 'no inflation' regime, the government, aware of its inability to make inflation commitments, effectively renounces its ability to deflate debt away. Under our baseline calibration for the relative weight on inflation disutility in households' preferences, $\psi$, we have found that giving up such discretionary stabilization tool actually increases welfare. As explained in section 2.3.3, such a scenario can be interpreted as the government issuing foreign currency debt, or joining a monetary union with a very strong anti-inflationary stance. We also argued that one could view the 'no inflation' regime as a situation in which the government appoints an independent central banker with an extremely great distaste for inflation.

In this section, we consider an intermediate arrangement by which the government delegates (discretionary) monetary policy to an independent central banker whose distaste for inflation is greater than that of society, but not so extreme as to imply zero inflation at all times. The question here is whether one can find intermediate preferences towards inflation that achieve better welfare outcomes than the two regimes considered thus far.

Formally, our maximization problem is modified as follows. On the one hand, the benevolent government retains the primary deficit and default decisions, taking as given the inflation policy function of the independent monetary authority, which we denote by $\tilde{\pi}(b)$. With a slight abuse of notation, let $V(b)$ denote the value function of the government when the latter no longer chooses inflation. The corresponding HJB equation is

$$
\rho V(b)=\max _{c, b^{*}}\left\{\log (1+c)-\frac{\psi}{2} \tilde{\pi}(b)^{2}+\left[\left(r(b)+\sigma^{2}-\mu-\tilde{\pi}(b)\right) b+\frac{c}{Q(b)}\right] V^{\prime}(b)+\frac{(\sigma b)^{2}}{2} V^{\prime \prime}(b)\right\},
$$

where the value matching and smooth pasting conditions are given again by equations (12) and (13), respectively. ${ }^{38}$ The optimal primary deficit ratio is given again by equation (15). Investors' bond pricing schedule $Q(b)$ is determined exactly as before.

The monetary authority chooses inflation taking as given the government's primary deficit policy, $c(b)$, and optimal default threshold, $b^{*}$. Letting $\tilde{V}(b)$ denote the monetary authority's

\footnotetext{
${ }^{38}$ In equation (24), we have used the definition of the bond yield $r(b)$ (equation 20) for compactness.
} 
value function, the latter satisfies the following HJB equation,

$$
\rho \tilde{V}(b)=\max _{\pi}\left\{\log (1+c(b))-\frac{\tilde{\psi}}{2} \pi^{2}+\left[\left(r(b)+\sigma^{2}-\mu-\pi\right) b+\frac{c(b)}{Q(b)}\right] \tilde{V}^{\prime}(b)+\frac{(\sigma b)^{2}}{2} \tilde{V}^{\prime \prime}(b)\right\},
$$

where $\tilde{\psi} \geq \psi$ captures the central banker's distaste for inflation. $\tilde{V}$ also satisfies a value matching condition analogous to (12). The optimal inflation decision is given by equation (16) with $\tilde{\psi}$ and $\tilde{V}^{\prime}$ replacing and $\psi$ and $V^{\prime}$, which defines the new inflation policy function $\tilde{\pi}(b)$. Notice that $\lim _{\tilde{\psi} \rightarrow \infty} \tilde{\pi}(b)=0$ for all $b$. Thus, as argued in section 2.3.3, the 'no inflation' regime can be viewed as an extreme case of the independent central banker problem laid out here, in which the latter has an arbitrarily great distaste for inflation.

In order to solve this problem we need to extend the numerical algorithm introduced in section 3.1. In particular, we replace the government problem (step 1) by:

Step 1a: Government problem. Given $Q^{(n-1)}, \pi^{(n-1)}$ and $b_{(n-1)}^{*}$, we solve the HJB equation $(24)$ in the domain $\left[0, b_{(n-1)}^{*}\right]$ imposing the smooth pasting condition (13) to obtain an estimate of the government's value function $V^{(n)}$ and of primary deficit $c^{(n)}$.

Step 1b: Central bank problem. Given $Q^{(n-1)}, c^{(n)}$ and $b_{(n-1)}^{*}$, we solve the HJB equation (25) in the domain $\left[0, b_{(n-1)}^{*}\right]$ imposing the smooth pasting condition (13) to obtain an estimate of the central bank's value function $\tilde{V}^{(n)}$ and of inflation $\pi^{(n)}$.

Figure 5 displays the unconditional means of social welfare and other relevant variables as we vary the conservative central banker's distaste for inflation, $\tilde{\psi} \cdot{ }^{39}$ The main message is that average social welfare increases monotonically with the inflation conservatism of the delegated monetary authority, but it is always lower than that achieved in the no-inflation regime, which is reached only asymptotically $(\tilde{\psi} \rightarrow \infty)$.

To understand this result, the figure also displays the contribution of consumption utility and inflation disutility to average welfare. On the one hand, central bank conservativeness reduces the average welfare due to consumption. Intuitively, the economy is more likely to default and hence to incur output losses when the monetary authority is more focused on stabilizing inflation. On the other hand, central bank conservativeness also reduces the average welfare costs of inflation. In fact, the latter effect clearly outweighs the first one, which explains the increase in overall welfare. Interestingly, we also find that a more conservative monetary authority reduces average nominal interest rates, reflecting once again the fact the ensuing reduction in average inflation premia

\footnotetext{
${ }^{39}$ To facilitate interpretation, the x-axes in Figure 5 display the central banker's distaste for inflation relative to that of society, $\tilde{\psi} / \psi$, where $\psi$ is held constant at its calibrated value (see Table 1 ). Thus $\tilde{\psi} / \psi=1$ represents our baseline 'inflationary regime' in which inflation is chosen by the benevolent government.
} 

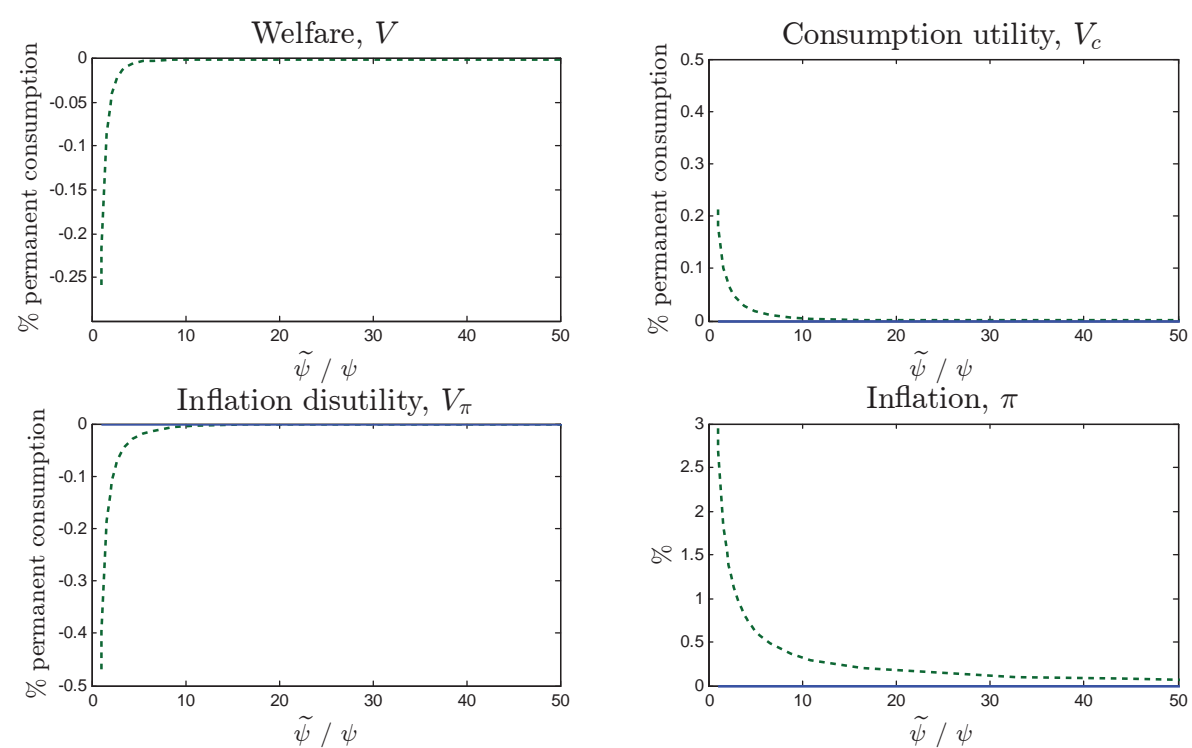

Inflation, $\pi$
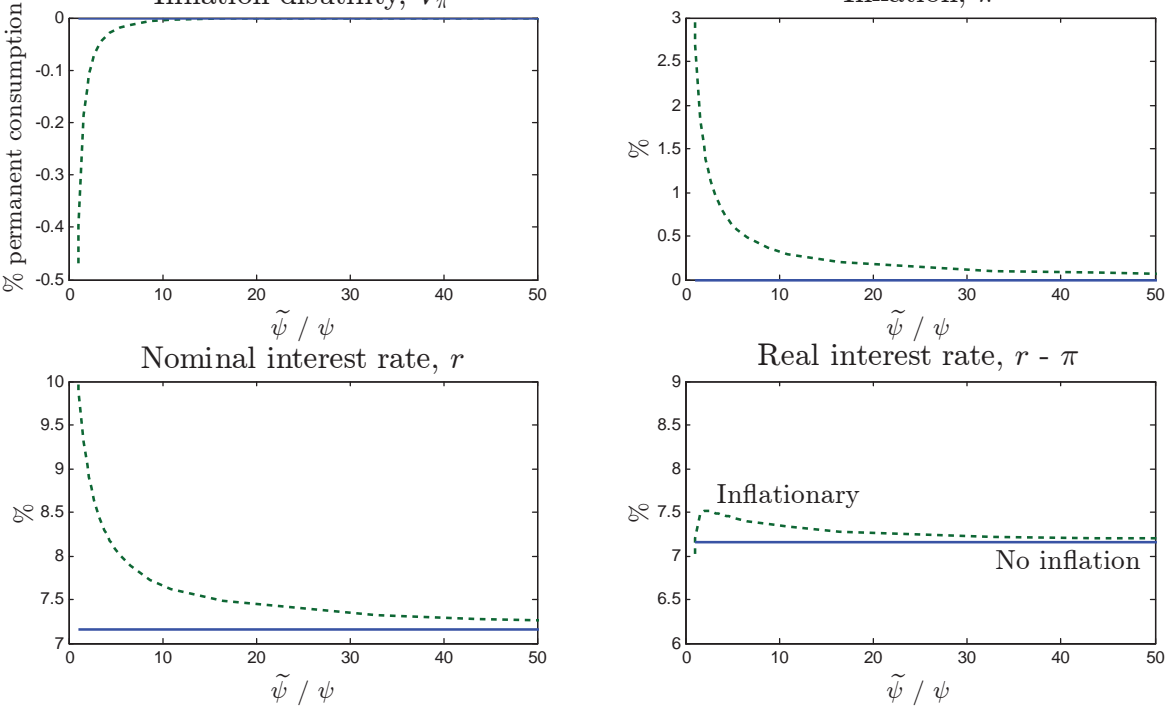

Figure 5: Effect of central bank conservatism under monetary policy delegation (average values). 
dominates the increase in average risk premia. Beyond a certain degree of conservativeness, it also reduces average real interest rates, as the reduction in average yields outpaces that in average inflation.

To summarize our results in this section, we find that if the government is unable to make credible commitments, delegating monetary policy to an independent, relatively conservative central banker achieves better welfare outcomes by reducing current and expected inflation. However, such an institutional solution continues to be dominated by a scenario in which the government fully renounces the ability to deflate debt away, as would be exemplified e.g. by issuing foreign currency debt or joining a monetary union with a very strong and credible anti-inflationary mandate.

\section{Conclusions}

Motivated by the recent debt crisis in the EMU periphery, in this paper we have analyzed the trade-offs between price stability and the sustainability of sovereign debt. We have done so in the context of a continuous-time, small open economy model where a benevolent government issues nominal defaultable debt to foreign investors. The government is assumed to be unable to make credible commitments regarding fiscal policy (including the possibility of defaulting on sovereign debt) and monetary policy. At each point in time the government optimally chooses primary deficit and inflation, and whether to default or not. A main theme of our paper is to compare this situation with an alternative scenario in which the government effectively renounces the option to deflate debt away, e.g. by issuing foreign currency debt or joining an anti-inflationary monetary union. In our quantitative exploration, the government's inflation tolerance is calibrated to replicate observed inflation differentials in the EMU periphery before the start of the euro.

We have found that giving up the option to deflate debt away achieves higher welfare (both at any debt ratio and on average) than retaining such discretionary adjustment margin. The reason lies in the costs and benefits of discretionary inflation. On the one hand, inflation allows reducing the real value of nominal debt (debt deflation effect) and thus making it more sustainable ceteris paribus, with the resulting reduction in risk premia. On the other hand, inflation creates direct welfare costs. Moreover, (expected) inflation raises the inflation premium that the government must offer in new bond issuances. In equilibrium, the latter effect clearly dominates the reduction in risk premia, thus producing an increase in bond yields that essentially undoes the debt deflation effect. As a result, the welfare costs of inflation dominate its benefits.

Our results thus qualify the conventional wisdom that national governments should benefit from retaining the possibility of deflating away their sovereign debt, in the sense that such a benefit may not materialize if such governments are unable to make credible commitments about its future monetary policy. This qualification may be particularly relevant for most EMU peripheral 
economies, in view of their inflation record (relative e.g. to that of Germany) in the decades prior to joining the euro.

Looking ahead, we note that we have analyzed the problem of a single government in a small open economy setup. Given our interest in recent developments in the euro area, we believe that extending the analysis presented here to the case of a monetary union with a common monetary authority and many national fiscal authorities that differ in their outstanding sovereign debt levels is of great importance. We leave this task for future research.

\section{References}

[1] Achdou, Y., J.-M. Lasry, P.-L. Lions and B. Moll (2014), "Heterogeneous Agent Models in Continuous Time," mimeo, Princeton University.

[2] Aguiar, M., M. Amador, E. Farhi and G. Gopinath (2013). "Crisis And Commitment: Inflation Credibility And The Vulnerability To Sovereign Debt Crises", mimeo.

[3] Aguiar, M., M. Amador, E. Farhi and G. Gopinath (2015). "Coordination And Crisis In Monetary Unions", forthcoming, Quarterly Journal of Economics

[4] Aguiar, M. and G. Gopinath (2006), "Defaultable debt, interest rates and the current account," Journal of International Economics, 69(1), 64-83.

[5] Araujo, A., M. Leon and R. Santos (2013), "Welfare analysis of currency regimes with defaultable debts," Journal of International Economics, 89(1), 143-153.

[6] Arellano, C. (2008). "Default Risk and Income Fluctuations in Emerging Economies," American Economic Review, 98(3), 690-712.

[7] Bacchetta, P., E. Perazzi and E. van Wincoop (2015). Self-Fulfilling Debt Crises: Can Monetary Policy Really Help?, working paper

[8] Barles, G., C. Daher, and M. Romano (1995), "Convergence of numerical schemes for parabolic equations arising in finance theory," Mathematical Models and Methods in Applied Sciences (5), 125-143.

[9] Barles, G. and P. E. Souganidis (1991), "Convergence of Approximation Schemes for Fully Nonlinear Second Order Equations," J. Asymptotic Analysis, 4, pp. 271-283.

[10] Benjamin, D. and M. L. J. Wright (2009), "Recovery Before Redemption: A Theory of Delays in Sovereign Debt Renegotiations", mimeo. 
[11] Calvo, G. (1988), "Servicing the Public Debt: The Role of Expectations," American Economic Review, 1988, 78, 647-661.

[12] Camous, A. and R. Cooper (2014), "Monetary Policy and Debt Fragility", NBER Working Paper No. 20650.

[13] Chatterjee, S. and B. Eyigungor (2012), "Maturity, Indebtedness, and Default Risk," American Economic Review, 102(6), 2674-99.

[14] Clarida, R., J. Galí and M. Gertler (1999). "The Science of Monetary Policy: A New Keynesian Perspective," Journal of Economic Literature, 37(4), 1661-1707.

[15] Cole, H. and T. Kehoe (2000), "Self-Fulfilling Debt Crises," Review of Economic Studies, 2000, 67, 91-116.

[16] Corsetti, G. and L. Dedola (2014), "The Mystery of the Printing Press: Self-Fulfilling Debt Crises and Monetary Sovereignty," mimeo.

[17] Crandall, M. G., H. Ishii, and P.-L. Lions (1992), "User's guide to viscosity solutions of second order partial differential equations." ArXiv Mathematics e-prints.

[18] Crandall, M. G., and P.-L. Lions (1983), "Viscosity Solutions of Hamilton-Jacobi Equations." Transactions of the American Mathematical Society, 277(1), pp. 1-42.

[19] Cruces, J.J., Buscaglia, M., Alonso, J. (2002), "The term structure of country risk and valuation in emerging markets," Manuscript, Universidad Nacional de La Plata.

[20] Cruces, J., and Trebesch, C., (2011), "Sovereign Defaults:The Price of Haircuts," CESifo Working Paper 3604.

[21] Da-Rocha, J. M., E. L. Giménez and F. X. Lores, 2013. "Self-fulfilling crises with default and devaluation," Economic Theory, 53(3), 499-535.

[22] Dias, D. A. and C. Richmond (2007), "Duration of Capital Market Exclusion: An Empirical Investigation," Working Paper, UCLA.

[23] Dixit, A. and R. S. Pindyck (1994), Investment under Uncertainty, Princeton University Press.

[24] Du, W. and J. Schreger (2015). "Sovereign Risk, Currency Risk, and Corporate Balance Sheets", mimeo

[25] Eaton, J. and M. Gersovitz (1981), "Debt with Potential Repudiation: Theoretical and Empirical Analysis," Review of Economic Studies, 48(2), 289-309. 
[26] Grauwe, P. D. (2011), "Only A More Active ECB Can Solve the Euro Crisis," The Center for Economic Policy Studies Policy Brief, 250, 1-8.

[27] Hatchondo, J. C. and L. Martinez (2009), "Long-duration bonds and sovereign defaults," Journal of International Economics, 79(1), 117-125.

[28] Krugman, P., "Wonking Out About the Euro Crisis (Very Wonkish)," (2011). http://krugman.blogs.nytimes.com/2011/08/08/wonking-out-about-the-euro-crisis-very wonkish/

[29] Leland H. (1994). "Corporate debt value, bond covenants, and optimal capital structure." Journal of Finance 49, 1213-52.

[30] Lohmann, S. (1992). "Optimal Commitment in Monetary Policy: Credibility versus Flexibility", American Economic Review, 82(1), 273-286 .

[31] Mendoza, E. and V. Z. Yue (2012). "A General Equilibrium Model of Sovereign Default and Business Cycles," Quarterly Journal of Economics, 127(2), 889-946.

[32] Merton R. C. (1974). "On the pricing of corporate debt: the risk structure of interest rates." Journal of Finance 29, 449-70.

[33] Nuño, G. and B. Moll (2014), "Optimal Control with Heterogeneous Agents in Continuous Time," mimeo.

[34] Oksendal, B. and A. Sulem (2007). Applied Stochastic Control of Jump Diffusions. Springer.

[35] Reis, R. (2013). "The Mystique Surrounding the Central Bank's Balance Sheet, Applied to the European Crisis," American Economic Review, 103(3), 135-40.

[36] Rogoff, K. (1985), "The Optimal Degree of Commitment to an Intermediate Monetary Target," Quarterly Journal of Economics, 100(4), 1169-89.

[37] Stokey, N. (2009). The Economics of Inaction, Princeton University Press.

[38] Sundaresan, S. (2013) "A Review of Merton's Model of the Firm's Capital Structure with its Wide Applications," Annual Review of Financial Economics, 5(5).1-5.21

[39] Sunder-Plassmann, L. (2014). "Inflation, default, and the denomination of sovereign debt", mimeo.

[40] Yue, V. Z. (2010). "Sovereign default and debt renegotiation," Journal of International Economics, 80(2), 176-187. 


\section{Appendix}

\section{A. Numerical algorithm}

We describe the numerical algorithm used to jointly solve for the equilibrium value function, $V(b)$, and bond price function, $Q(b)$. The algorithm proceeds in 3 steps. We describe each step in turn.

\section{Step 1: Solution to the Hamilton-Jacobi-Bellman equation}

The HJB equation (14) is solved using an upwind finite difference scheme following Achdou et al. (2014). It approximates the value function $V(b)$ on a finite grid with step $\Delta b: b \in\left\{b_{1}, \ldots, b_{I}\right\}$, where $b_{i}=b_{i-1}+\Delta b=b_{1}+(i-1) \Delta b$ for $2 \leq i \leq I$. The bounds are $b_{1}=0$ and $b_{I}=b^{*}-\Delta b$, such that $\Delta b=b^{*} / I$. We choose $\theta$ such that $\theta(I+1) \in \mathbb{N}$. We use the notation $V_{i} \equiv V\left(b_{i}\right), i=1, \ldots, I$, and similarly for the bond price function $Q_{i}$ and the policy functions $\left(\pi_{i}, c_{i}\right)$.

Notice first that the HJB equation involves first and second derivatives of the value function, $V^{\prime}(b)$ and $V^{\prime \prime}(b)$. At each point of the grid, the first derivative can be approximated with a forward $(F)$ or a backward $(B)$ approximation,

$$
\begin{aligned}
V^{\prime}\left(b_{i}\right) & \approx \partial_{F} V_{i} \equiv \frac{V_{i+1}-V_{i}}{\Delta b}, \\
V^{\prime}\left(b_{i}\right) & \approx \partial_{B} V_{i} \equiv \frac{V_{i}-V_{i-1}}{\Delta b},
\end{aligned}
$$

whereas the second derivative is approximated by

$$
V^{\prime \prime}\left(b_{i}\right) \approx \partial_{b b} V_{i} \equiv \frac{V_{i+1}+V_{i-1}-2 V_{i}}{(\Delta b)^{2}} .
$$

In an upwind scheme, the choice of forward or backward derivative depends on the sign of the drift function for the state variable, given by

$$
s(b) \equiv\left(\frac{\lambda+\delta}{Q(b)}+\sigma^{2}-\mu-\lambda-\pi(b)\right) b+\frac{c(b)}{Q(b)},
$$

for $b \leq b^{*}$, where

$$
\begin{aligned}
c(b) & =-\frac{Q(b)}{V^{\prime}(b)}-1, \\
\pi(\pi) & =-\frac{b}{\psi} V^{\prime}(b)=\frac{b Q(b)}{\psi(1+c)} .
\end{aligned}
$$

Let superscript $n$ denote the iteration counter. The HJB equation is approximated by the following 
upwind scheme,

$\frac{V_{i}^{n+1}-V_{i}^{n}}{\Delta}+\rho V_{i}^{n+1}=\log \left(c_{i}^{n}+1\right)-\frac{\psi}{2}\left(\pi_{i}^{n}\right)^{2}+\partial_{F} V_{i}^{n+1} s_{i, F}^{n} \mathbf{1}_{s_{i, F}^{n}>0}+\partial_{B} V_{i}^{n+1} s_{i, B}^{n} \mathbf{1}_{s_{i, B}^{n}<0}+\frac{\left(\sigma b_{i}\right)^{2}}{2} \partial_{b b} V_{i}^{n+1}$,

for $i=1, \ldots, I$, where $\mathbf{1}(\cdot)$ is the indicator function and

$$
\begin{aligned}
& s_{i, F}^{n}=\left(\frac{\lambda+\delta}{Q_{i}}+\sigma^{2}-\mu-\lambda+\frac{b_{i}}{\psi} \partial_{F} V_{i}^{n}\right) b_{i}-\left(\frac{1}{\partial_{F} V_{i}^{n}}+\frac{1}{Q_{i}}\right), \\
& s_{i, B}^{n}=\left(\frac{\lambda+\delta}{Q_{i}}+\sigma^{2}-\mu-\lambda+\frac{b_{i}}{\psi} \partial_{B} V_{i}^{n}\right) b_{i}-\left(\frac{1}{\partial_{B} V_{i}^{n}}+\frac{1}{Q_{i}}\right) .
\end{aligned}
$$

Therefore, when the drift is positive $\left(s_{i, F}^{n}>0\right)$ we employ a forward approximation of the derivative, $\partial_{F} V_{i}^{n+1}$; when it is negative $\left(s_{i, B}^{n}<0\right)$ we employ a backward approximation, $\partial_{B} V_{i}^{n+1}$. The term $\frac{V_{i}^{n+1}-V_{i}^{n}}{\Delta} \rightarrow 0$ as $V_{i}^{n+1} \rightarrow V_{i}^{n}$. Moving all terms involving $V^{n+1}$ to the left hand side and the rest to the right hand side, we obtain

$$
V_{i-1}^{n+1} \alpha_{i}^{n}+V_{i}^{n+1} \beta_{i}^{n}+V_{i+1}^{n+1} \xi_{i}^{n}=\log \left(c_{i}^{n}+1\right)-\frac{\psi}{2}\left(\pi_{i}^{n}\right)^{2}+\frac{V_{i}^{n}}{\Delta}
$$

where

$$
\begin{aligned}
\alpha_{i}^{n} & \equiv \frac{s_{i, B}^{n} \mathbf{1}_{s_{i, B}^{n}<0}}{\Delta b}-\frac{\left(\sigma b_{i}\right)^{2}}{2(\Delta b)^{2}}, \\
\beta_{i}^{n} & \equiv \frac{1}{\Delta}+\rho+\frac{s_{i, F}^{n} \mathbf{1}_{s_{i, F}^{n}>0}}{\Delta b}-\frac{s_{i, B}^{n} \mathbf{1}_{s_{i, B}^{n}<0}}{\Delta b}+\frac{\left(\sigma b_{i}\right)^{2}}{(\Delta b)^{2}} \\
\xi_{i}^{n} & \equiv-\frac{s_{i, F}^{n} \mathbf{1}_{s_{i, F}^{n}>0}}{\Delta b}-\frac{\left(\sigma b_{i}\right)^{2}}{2(\Delta b)^{2}}
\end{aligned}
$$

for $i=1, \ldots, I$. Notice that the state constraint $b \geq 0$ means that $s_{1, B}^{n}=0$, which together with $b_{1}=0$ implies $\alpha_{1}^{n}=0$. In equation (30), the optimal primary deficit ratio is set to

$$
c_{i}^{n}=\left(\frac{-Q_{i}^{n}}{\partial V_{i}^{n}}-1\right),
$$

where

$$
\partial V_{i}=\partial_{F} V_{i} \mathbf{1}_{s_{i, F}^{n}>0}+\partial_{B} V_{i} \mathbf{1}_{s_{i, B}^{n}<0}-\frac{Q\left(b_{i}\right)}{1+\bar{c}_{i}} \mathbf{1}_{s_{i, F}^{n}<0} \mathbf{1}_{s_{i, B}^{n} \geq 0} .
$$

In the above expression, $\bar{c}_{i}$ is the consumption level such that $s\left(b_{i}\right) \equiv s_{i}^{n}=0$, i.e. it solves

$$
\left(\frac{\lambda+\delta}{Q_{i}}+\sigma^{2}-\mu-\lambda-\frac{b_{i} Q_{i}}{\psi\left(1+\bar{c}_{i}\right)}\right) b_{i}+\frac{\bar{c}_{i}}{Q_{i}}=0
$$


The solution is the higher root of the above equation,

$$
\bar{c}_{i}=\frac{-\left(1+\Gamma_{i} Q_{i}\right)+\sqrt{\left(1+\Gamma_{i} Q_{i}\right)^{2}-4\left[\Gamma_{i} Q_{i}-\frac{b_{i}^{2} Q_{i}^{2}}{\psi}\right]}}{2},
$$

where $\Gamma_{i} \equiv\left(\frac{\lambda+\delta}{Q\left(b_{i}\right)}+\sigma^{2}-\mu-\lambda\right) b_{i}$. Given $c_{i}^{n}$, the optimal inflation rate is

$$
\pi_{i}^{n}=\frac{b Q_{i}}{\psi\left(1+c_{i}^{n}\right)}
$$

The smooth pasting boundary condition (equation 13 ) can be approximated by ${ }^{40}$

$$
\frac{V_{I+1}^{n+1}-V_{I}^{n+1}}{\Delta b}=-\frac{\epsilon}{\chi+\rho}+\frac{\chi}{\chi+\rho} \theta \partial_{F} V_{\theta(I+1)}^{n} \Rightarrow V_{I+1}^{n+1}=V_{I}^{n+1}+\left(-\frac{\epsilon}{\chi+\rho}+\frac{\chi}{\chi+\rho} \theta \partial_{F} V_{\theta(I+1)}^{n}\right) \Delta b .
$$

Equation (30) is a system of $I$ linear equations which can be written in matrix notation as:

$$
\mathbf{A}^{n} \mathbf{V}^{n+1}=\mathbf{d}^{n}
$$

where the matrix $\mathbf{A}^{n}$ and the vectors $\mathbf{V}^{n+1}$ and $\mathbf{d}^{n}$ are defined by

$$
\begin{array}{r}
\mathbf{A}^{n}=\left[\begin{array}{cccccc}
\beta_{1}^{n} & \xi_{1}^{n} & 0 & 0 & \cdots & 0 \\
\alpha_{2}^{n} & \beta_{2}^{n} & \xi_{2}^{n} & 0 & \cdots & 0 \\
0 & \alpha_{3}^{n} & \beta_{3}^{n} & \xi_{3}^{n} & \cdots & 0 \\
\vdots & \ddots & \ddots & \ddots & \ddots & \ddots \\
0 & 0 & \cdots & \alpha_{I-1}^{n} & \beta_{I-1}^{n} & \xi_{I-1}^{n} \\
0 & 0 & \cdots & 0 & \alpha_{I}^{n} & \beta_{I}^{n}+\xi_{I}^{n}
\end{array}\right], \quad \mathbf{V}^{n+1}=\left[\begin{array}{c}
V_{1}^{n+1} \\
V_{2}^{n+1} \\
V_{3}^{n+1} \\
\vdots \\
V_{I-1}^{n+1} \\
V_{I}^{n+1}
\end{array}\right] \\
\mathbf{d}^{n}=\left[\begin{array}{c}
\log \left(c_{1}^{n}+1\right)-\frac{\psi}{2}\left(\pi_{1}^{n}\right)^{2}+\frac{V_{1}^{n}}{\Delta} \\
\log \left(c_{2}^{n}+1\right)-\frac{\psi}{2}\left(\pi_{2}^{n}\right)^{2}+\frac{V_{2}^{n}}{\Delta} \\
\log \left(c_{3}^{n}+1\right)-\frac{\psi}{2}\left(\pi_{3}^{n}\right)^{2}+\frac{V_{3}^{n}}{\Delta} \\
\log \left(c_{I}^{n}+1\right)-\frac{\psi}{2}\left(\pi_{I}^{n}\right)^{2}+\frac{V_{I}^{n}}{\Delta}+\xi_{I}^{n}\left(\frac{\epsilon}{\chi+\rho}-\frac{\chi}{\chi+\rho} \theta \partial_{F} V_{\theta(I+1)}^{n}\right) \Delta b
\end{array}\right] .
\end{array}
$$

Notice that the element $(I, I)$ in $A$ is $\beta_{I}^{n}+\xi_{I}^{n}$ due to the smooth pasting condition (33).

\footnotetext{
${ }^{40}$ Notice that we solve for the value function under the guess that the optimal default threshold satisfies $b^{*}>\hat{b}$, such that $\max \left\{0, b^{*}-\hat{b}\right\}=b^{*}-\hat{b}$. We verify that our guess is satisfied in equilibrium in all our simulations.
} 
The algorithm to solve the HJB equation runs as follows. Begin with an initial guess $V_{i}^{0}=-b_{i}$, $i=1, \ldots, I$. Set $n=0$. Then:

1. Compute $\partial_{F} V_{i}^{n}, \partial_{B} V_{i}^{n}$ and $\partial_{b b} V_{i}^{n}$ using (26)-(28).

2. Compute $c_{i}^{n}$ and $\pi_{i}^{n}$ using (31) and (32).

3. Find $V_{i}^{n+1}$ solving the linear system of equations (34).

4. If $V_{i}^{n+1}$ is close enough to $V_{i}^{n}$, stop. If not set $n:=n+1$ and go to 1 .

\section{Step 2: Solution to the Bond Pricing Equation}

The pricing equation (18) is also solved using an upwind finite difference scheme. The equation in this case is

$$
Q(b)(\bar{r}+\pi(b)+\lambda)=(\lambda+\delta)+\left[\left(\frac{\lambda+\delta}{Q(b)}+\sigma^{2}-\mu-\lambda-\pi(b)\right) b+\frac{c(b)}{Q(b)}\right] Q^{\prime}(b)+\frac{(\sigma b)^{2}}{2} Q^{\prime \prime}(b),
$$

with a boundary condition

$$
Q\left(b^{*}\right)=\frac{\chi}{\bar{r}-\mu+\chi} \theta Q\left(\theta b^{*}\right) .
$$

This case is similar to the HJB equation. Using the notation $Q_{i}=Q\left(b_{i}\right)$, the equation can be expressed as

$\frac{Q_{i}^{n+1}-Q_{i}^{n}}{\Delta}+Q_{i}^{n+1}\left(\bar{r}+\pi_{i}+\lambda\right)=\lambda+\delta+\partial_{F} Q_{i}^{n+1} s_{i, F}^{n} \mathbf{1}_{s_{i, F}^{n}>0}+\partial_{B} Q_{i}^{n+1} s_{i, B}^{n} \mathbf{1}_{s_{i, B}^{n}<0}+\frac{\left(\sigma b_{i}\right)^{2}}{2} \partial_{b b} Q_{i}^{n+1}$,

where:

$$
\begin{aligned}
Q^{\prime}\left(b_{i}\right) & \approx \partial_{F} Q_{i} \equiv \frac{Q_{i+1}-Q_{i}}{\Delta b} \\
Q^{\prime}\left(b_{i}\right) & \approx \partial_{B} Q_{i} \equiv \frac{Q_{i}-Q_{i-1}}{\Delta b} \\
Q^{\prime \prime}\left(b_{i}\right) & \approx \partial_{b b} Q_{i} \equiv \frac{Q_{i+1}+Q_{i-1}-2 Q_{i}}{(\Delta b)^{2}}
\end{aligned}
$$

and rearranging terms

$$
\begin{aligned}
Q_{i-1}^{n+1} \alpha_{i}^{n}+Q_{i}^{n+1}\left(\beta_{i}^{n}+\bar{r}+\pi_{i}+\lambda-\rho\right)+Q_{i+1}^{n+1} \xi_{i}^{n} & =\lambda+\delta+\frac{Q_{i}^{n}}{\Delta}, \forall i<I+1, \\
Q_{I+1} & =\frac{\chi}{\rho-\mu+\chi} \theta Q(\theta(I+1)) .
\end{aligned}
$$


Notice the abuse of notation, as

$$
s_{i, F}^{n}=s_{i, B}^{n}=s_{i}^{n}=\left(\frac{\lambda+\delta}{Q^{n}\left(b_{i}\right)}+\sigma^{2}-\mu-\lambda-\pi_{i}\right) b_{i}+\frac{c_{i}}{Q^{n}\left(b_{i}\right)} .
$$

Equation (36) is again a system of $I$ linear equations which can be written in matrix notation as:

$$
\mathbf{F}^{n} \mathbf{Q}^{n+1}=\mathbf{q}^{n}
$$

where the matrix $\mathbf{F}^{n}$ and the vectors $\mathbf{Q}^{n+1}$ and $\mathbf{f}^{n}$ are defined by:

$$
\begin{aligned}
& \mathbf{F}^{n}=\left[\begin{array}{ccccc}
\left(\beta_{1}^{n}+\pi_{1}\right. & \xi_{1}^{n} & 0 & \ldots & 0 \\
+\lambda+\bar{r}-\rho) & \left(\beta_{2}^{n}+\pi_{2}\right. & \xi_{2}^{n} & \ldots & 0 \\
\alpha_{2}^{n} & +\lambda+\bar{r}-\rho) & \left(\beta_{3}^{n}+\pi_{3}\right. & \ldots & 0 \\
0 & \alpha_{3}^{n} & +\lambda+\bar{r}-\rho) & \cdots & \ddots \\
\vdots & \ddots & \ddots & \ddots & \xi_{I-1}^{n} \\
0 & 0 & \ldots & +\lambda+\bar{r}-\rho) & \left(\beta_{I}^{n}+\pi_{I}\right. \\
0 & 0 & \ldots & \alpha_{I}^{n} & +\lambda+\bar{r}-\rho)
\end{array}\right], \\
& \mathbf{Q}^{n+1}=\left[\begin{array}{c}
Q_{1}^{n+1} \\
Q_{2,1}^{n+1} \\
Q_{3,1}^{n+1} \\
\vdots \\
Q_{I-1}^{n+1} \\
Q_{I}^{n+1}
\end{array}\right], \quad \mathbf{q}^{n}=\left[\begin{array}{c}
\lambda+\delta+\frac{Q_{1}^{n}}{\Delta} \\
\lambda+\delta+\frac{Q_{2}^{n}}{\Delta} \\
\lambda+\delta+\frac{Q_{3}^{n}}{\Delta} \\
\vdots \\
\lambda+\delta+\frac{Q_{I-1}^{n}}{\Delta} \\
\lambda+\delta+\frac{Q_{I}^{n}}{\Delta}-\xi_{I}^{n} \frac{\chi}{\rho-\mu+\chi} \theta Q_{\theta(I+1)}^{n}
\end{array}\right] .
\end{aligned}
$$

The algorithm to solve the bond pricing equation is similar to the HJB. Begin with an initial guess $Q_{i}^{0}=\frac{\lambda+\delta}{\bar{r}+\lambda}$, set $n=0$. Then:

1. Find $Q_{i}^{n+1}$ solving the linear system of equations (37).

2. If $Q_{i}^{n+1}$ is close enough to $Q_{i}^{n}$, stop. If not set $n:=n+1$ and go to 1 . 


\section{Step 3: Value Matching}

Finally, we iterate until the value matching condition (12) is satisfied:

$$
V_{I+1}=-\frac{\max \left\{0, b_{I+1}-\hat{b}\right\}}{\rho+\chi}+\frac{\chi}{\chi+\rho} V_{\theta(I+1)} .
$$

Taking into account (33), condition (38) can be rewritten as

$$
V_{I}+\left(-\frac{\epsilon}{\chi+\rho}+\frac{\chi}{\chi+\rho} \theta \partial_{F} V_{\theta(I+1)}\right) \Delta b+\frac{\max \left\{0, b_{I+1}-\hat{b}\right\}}{\rho+\chi}-\frac{\chi}{\chi+\rho} V_{\theta(I+1)}=0 .
$$

\section{B. The riskless nominal bond}

We define a new instrument, a riskless nominal bond. This is a non-defaultable bond issued in the domestic currency. In this case, the nominal price of the bond for a current debt ratio $b \leq b^{*}$ is given by

$$
\tilde{Q}(b)=\mathbb{E}\left[\begin{array}{c}
\int_{0}^{T\left(b^{*}\right)} e^{-(\bar{r}+\lambda) t-\int_{0}^{t} \pi_{s} d s}(\lambda+\delta) d t \\
+\int_{T\left(b^{*}\right)}^{T\left(b^{*}\right)+\tau} e^{-(\bar{r}+\lambda) t-\int_{0}^{T\left(b^{*}\right)} \pi_{s} d s}(\lambda+\delta) d t+e^{-(\bar{r}+\lambda)\left(T\left(b^{*}\right)+\tau\right)-\int_{0}^{T\left(b^{*}\right)} \pi_{s} d s} \tilde{Q}\left(\theta b^{*}\right) \mid b_{0}=b
\end{array}\right] .
$$

Applying again the Feynman-Kac formula, we obtain

$$
\tilde{Q}(b)(\bar{r}+\pi(b)+\lambda)=(\lambda+\delta)+\left[\left(\frac{\lambda+\delta}{Q(b)}+\sigma^{2}-\mu-\lambda-\pi\right) b+\frac{c(b)}{Q(b)}\right] \tilde{Q}^{\prime}(b)+\frac{(\sigma b)^{2}}{2} \tilde{Q}^{\prime \prime}(b),
$$

for all $b \in\left[0, b^{*}\right)$. The boundary condition for $\tilde{Q}(b)$ is given by

$$
\begin{aligned}
\tilde{Q}\left(b^{*}\right) & =\mathbb{E}\left[\int_{0}^{\tau} e^{-(\bar{r}+\lambda) t}(\lambda+\delta) d t+e^{-(\bar{r}+\lambda) \tau} \tilde{Q}\left(\theta b^{*}\right)\right] \\
& =\int_{0}^{\infty} \chi e^{-\chi \tau}\left[\left(1-e^{-(\bar{r}+\lambda) \tau}\right) \frac{\lambda+\delta}{\bar{r}+\lambda} d t+e^{-(\bar{r}+\lambda) \tau} \tilde{Q}\left(\theta b^{*}\right)\right] d \tau \\
& =\frac{\lambda+\delta}{\bar{r}+\chi+\lambda}+\frac{\chi}{\bar{r}+\chi+\lambda} \tilde{Q}\left(\theta b^{*}\right) .
\end{aligned}
$$

Given the equilibrium default threshold $b^{*}$, we solve for the riskless bond price function $\tilde{Q}(b)$ using a finite difference scheme similar to the one used to solve for $Q(b)$ in Step 2 of the general algorithm. 


\section{Computing the expected time-to-default}

Given the definition of the expected time to default (21), applying the Feynman-Kac formula we obtain

$$
1+\left[\left(\frac{\lambda+\delta}{Q(b)}+\sigma^{2}-\mu-\lambda-\pi\right) b+\frac{c}{Q(b)}\right] T^{e \prime}(b)+\frac{(\sigma b)^{2}}{2} T^{e \prime \prime}(b)=0,
$$

with a boundary condition

$$
T^{e}\left(b^{*}\right)=0 .
$$

This can be solved using a finite difference scheme similar to the one described for the bond price in Appendix A.

\section{Solution to the Kolmogorov Forward equation}

Let $\tilde{f}(b)$ denote the stationary share of time spent at debt ratio $b$ while in good credit standing. It satisfies the following Kolmogorov Forward equation:

$$
0=-\frac{d}{d b}[s(b) \tilde{f}(b)]+\frac{1}{2} \frac{d^{2}}{d b^{2}}\left[(\sigma b)^{2} \tilde{f}(b)\right]+\chi \tilde{h} \delta\left(b-\theta b^{*}\right)-\chi \tilde{h} \delta\left(b-b^{*}\right)
$$

subject to

$$
1=\int_{0}^{b^{*}} \tilde{f}(b) d b+\tilde{h}
$$

where $s(b)$ is the drift function given by $(29), \tilde{h}$ is the stationary share of time spent in exclusion,

$$
\tilde{h} \equiv \frac{\mathbb{E}_{0}[\tau]}{\mathbb{E}_{0}\left[\tau+T\left(b^{*}\right) \mid b_{0}=\theta b^{*}\right]}=\frac{1 / \chi}{1 / \chi+T^{e}\left(\theta b^{*}\right)},
$$

and $\delta(\cdot)$ is the Dirac 'delta'. ${ }^{41}$ In equation (39), the term $\chi \tilde{h} \delta\left(b-\theta b^{*}\right)$ reflects the fact that the government reenters capital markets at $b=\theta b^{*}$ following exclusion spells, on which it spends a fraction $\tilde{h}$ of time and from which it exits at rate $\chi$. Similarly, the term $\chi \tilde{h} \delta\left(b-b^{*}\right)$ captures the fact that at $b=b^{*}$ the government defaults and hence exits the repayment spell; in the latter term, we use the fact that, in the ergodic limit, the flow of transitions from repayment to exclusion spells must equal the flow of transitions from exclusion to repayments spells, $\chi \tilde{h}$. We define $f(b) \equiv \frac{\tilde{f}(b)}{1-\tilde{h}}$,

${ }^{41}$ The Dirac delta is a distribution or generalized function such that $\delta[f]=\int_{-\varepsilon}^{\varepsilon} f(x) \delta(x) d x=f(0), \quad \forall \varepsilon>0$, $f \in L^{1}(-\varepsilon, \varepsilon)$. A heuristic characterization is the following:

$$
\begin{aligned}
\int_{\infty}^{\infty} \delta(x) d x & =1, \\
\delta(x) & =\left\{\begin{array}{cc}
\infty, & x=0 \\
0, & x \neq 0
\end{array}\right.
\end{aligned}
$$


which denotes the distribution of the debt ratio conditional on being in good credit standing. We also define $h \equiv \frac{\tilde{h}}{1-\tilde{h}}$. Equation (39) can then be written as,

$$
\begin{aligned}
0= & -\frac{d}{d b}\left\{\left[\left(\frac{\lambda+\delta}{Q(b)}+\sigma^{2}-\mu-\lambda-\pi(b)\right) b+\frac{c(b)}{Q(b)}\right] f(b)\right\}+\frac{1}{2} \frac{d^{2}}{d b^{2}}\left[(\sigma b)^{2} f(b)\right] \\
& +\chi h \delta\left(b-\theta b^{*}\right)-\chi h \delta\left(b-b^{*}\right),
\end{aligned}
$$

where now

$$
1=\int_{0}^{b^{*}} f(b) d b
$$

We solve the above equation using an upwind finite difference scheme as in Achdou et al. (2014) or Nuño and Moll (2015). We use the notation $f_{i} \equiv f\left(b_{i}\right)$. The system can be now expressed as

$$
\begin{aligned}
0= & -\frac{f_{i} s_{i, F} \mathbf{1}_{s_{i, F}^{n}>0}-f_{i-1} s_{i-1, F} \mathbf{1}_{s_{i-1, F}^{n}>0}}{\Delta b}-\frac{f_{i+1} s_{i+1, B} \mathbf{1}_{s_{i+1, B}^{n}}<0}{\Delta b}-f_{i} s_{i, B} \mathbf{1}_{s_{i, B}^{n}<0} \\
& +\frac{f_{i+1}\left(\sigma b_{i+1}\right)^{2}+f_{i-1}\left(\sigma b_{i-1}\right)^{2}-2 f_{i}\left(\sigma b_{i}\right)^{2}}{2(\Delta b)^{2}}+\chi h \mathbf{1}_{\theta(I+1)}-\chi h \mathbf{1}_{I+1},
\end{aligned}
$$

or equivalently

$$
f_{i-1} \xi_{i-1}+f_{i+1} \alpha_{i+1}+f_{i}\left(\beta_{i}-\frac{1}{\Delta}-\rho\right)=0 .
$$

The boundary conditions are $b \geq 0$ and $f\left(b^{*}\right)=0$. Therefore, (40) is also a system of $I$ linear equations which can be written in matrix notation as:

$$
\left(\mathbf{A}-\left(\frac{1}{\Delta}+\rho\right) \mathbf{I}-\xi_{I} \mathbf{1}_{I}\right)^{\mathbf{T}} \mathbf{f}=\mathbf{h},
$$

where $\left(\mathbf{A}-\left(\frac{1}{\Delta}+\rho\right) \mathbf{I}-\xi_{I} \mathbf{1}_{I}\right)^{\mathbf{T}}$ is the transpose of $\left(\mathbf{A}-\left(\frac{1}{\Delta}+\rho\right) \mathbf{I}-\xi_{I} \mathbf{1}_{I}\right)=\lim _{n \rightarrow \infty}\left(\mathbf{A}^{\mathbf{n}}-\left(\frac{1}{\Delta}+\rho\right) \mathbf{I}-\xi_{I}^{n} \mathbf{1}_{I}\right)$, and $\mathbf{A}^{\mathbf{n}}$ was defined in (35). $\mathbf{h}=\mathbf{1}_{I}-\mathbf{1}_{\theta(I+1)}$ is a vector of zeros with a +1 at position $I$ and $\mathbf{a}-1$ at position $\theta(I+1) .{ }^{42}$ We solve the system (41) and obtain a solution $\hat{\mathbf{f}}$. Then we renormalize as

$$
f_{i}=\frac{\hat{f}_{i}}{\sum_{i=1}^{I} \hat{f}_{i} \Delta b} .
$$

\section{E. Data Appendix}

Data on GDP, inflation and current account balance for the five EMU periphery countries (Greece, Italy, Ireland, Portugal and Spain), and inflation for the United States, come from the IMF's World

\footnotetext{
${ }^{42}$ Here we are approximating the exit point by $b^{*}-\Delta b$ instead of $b^{*}$, as the latter does not belong to the grid. Notice also how we do not include the term $\chi h$ due to the linearity and the rescaling of the system.
} 
Economic Outlook database. The inflation differential is computed as the difference between the average inflation in the EMU periphery and that of the United States for the period 1987-1997.

External public debt is "General Government Gross consolidated Debt held by non-residents of the Member State" and is taken from each country's national accounts. Sovereign risk premia (spreads) are the difference between the average yield on 10-year bonds of EMU periphery countries and that of German bonds, taken from Bloomberg. We use the yield on the German 10-year bond (also from Bloomberg) as the empirical proxy for the model's riskless yield, $\tilde{r}_{t}$. Bond yields for the pre-EMU period are annual and are taken from the European Commission's macroeconomic database (AMECO).

All data are annual except bond yields and risk premia which are quarterly. We stop the sample for yields and risk premia in 2012:Q2 (included) in order to isolate our analysis from the effects of the annoucement by the European Central Bank of the Outright MonetaryTransactions (OMT) programme in the summer of 2012.

\section{F. Value functions for alternative calibrations}



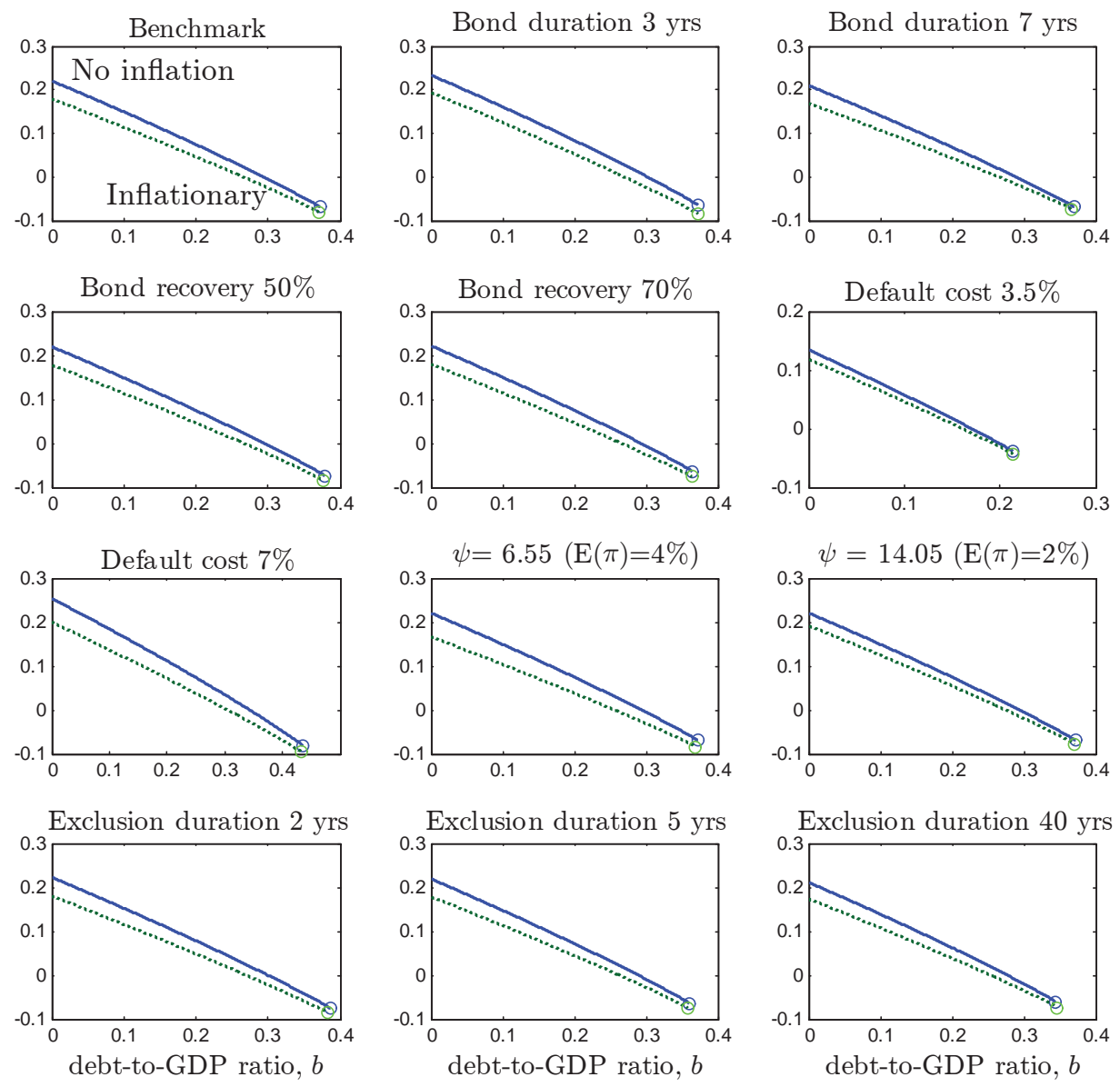

Figure 6: Value functions for alternative calibrations 


\section{BANCO DE ESPAÑA PUBLICATIONS}

\section{WORKING PAPERS}

1401 TERESA SASTRE and FRANCESCA VIANI: Countries' safety and competitiveness, and the estimation of current account misalignments.

1402 FERNANDO BRONER, ALBERTO MARTIN, AITOR ERCE and JAUME VENTURA: Sovereign debt markets in turbulent times: creditor discrimination and crowding-out effects.

1403 JAVIER J. PÉREZ and ROCÍO PRIETO: The structure of sub-national public debt: liquidity vs credit risks.

1404 BING XU, ADRIAN VAN RIXTEL and MICHIEL VAN LEUVENSTEIJN: Measuring bank competition in China: a comparison of new versus conventional approaches applied to loan markets.

1405 MIGUEL GARCÍA-POSADA and JUAN S. MORA-SANGUINETTI: Entrepreneurship and enforcement institutions: disaggregated evidence for Spain.

1406 MARIYA HAKE, FERNANDO LÓPEZ-VICENTE and LUIS MOLINA: Do the drivers of loan dollarisation differ between CESEE and Latin America? A meta-analysis.

1407 JOSÉ MANUEL MONTERO and ALBERTO URTASUN: Price-cost mark-ups in the Spanish economy: a microeconomic perspective.

1408 FRANCISCO DE CASTRO, FRANCISCO MARTÍ, ANTONIO MONTESINOS, JAVIER J. PÉREZ and A. JESÚS SÁNCHEZ-FUENTES: Fiscal policies in Spain: main stylised facts revisited.

1409 MARÍA J. NIETO: Third-country relations in the Directive establishing a framework for the recovery and resolution of credit institutions.

1410 ÓSCAR ARCE and SERGIO MAYORDOMO: Short-sale constraints and financial stability: evidence from the Spanish market.

1411 RODOLFO G. CAMPOS and ILIANA REGGIO: Consumption in the shadow of unemployment.

1412 PAUL EHLING and DAVID HAUSHALTER: When does cash matter? Evidence for private firms.

1413 PAUL EHLING and CHRISTIAN HEYERDAHL-LARSEN: Correlations.

1414 IRINA BALTEANU and AITOR ERCE: Banking crises and sovereign defaults in emerging markets: exploring the links.

1415 ÁNGEL ESTRADA, DANIEL GARROTE, EVA VALDEOLIVAS and JAVIER VALLÉS: Household debt and uncertainty: private consumption after the Great Recession.

1416 DIEGO J. PEDREGAL, JAVIER J. PÉREZ and A. JESÚS SÁNCHEZ-FUENTES: A toolkit to strengthen government budget surveillance.

1417 J. IGNACIO CONDE-RUIZ, and CLARA I. GONZÁLEZ: From Bismarck to Beveridge: the other pension reform in Spain.

1418 PABLO HERNÁNDEZ DE COS, GERRIT B. KOESTER, ENRIQUE MORAL-BENITO and CHRISTIANE NICKEL: Signalling fiscal stress in the euro area: a country-specific early warning system.

1419 MIGUEL ALMUNIA and DAVID LÓPEZ-RODRÍGUEZ: Heterogeneous responses to effective tax enforcement: evidence from Spanish firms.

1420 ALFONSO R. SÁNCHEZ: The automatic adjustment of pension expenditures in Spain: an evaluation of the 2013 pension reform.

1421 JAVIER ANDRÉS, ÓSCAR ARCE and CARLOS THOMAS: Structural reforms in a debt overhang.

1422 LAURA HOSPIDO and ENRIQUE MORAL-BENITO: The public sector wage premium in Spain: evidence from longitudinal administrative data.

1423 MARÍA DOLORES GADEA-RIVAS, ANA GÓMEZ-LOSCOS and GABRIEL PÉREZ-QUIRÓS: The Two Greatest. Great Recession vs. Great Moderation.

1424 ENRIQUE MORAL-BENITO and OLIVER ROEHN: The impact of financial (de)regulation on current account balances.

1425 MAXIMO CAMACHO and JAIME MARTINEZ-MARTIN: Real-time forecasting US GDP from small-scale factor models.

1426 ALFREDO MARTÍN OLIVER, SONIA RUANO PARDO and VICENTE SALAS FUMÁS: Productivity and welfare: an application to the Spanish banking industry.

1427 JAVIER ANDRÉS and PABLO BURRIEL: Inflation dynamics in a model with firm entry and (some) heterogeneity.

1428 CARMEN BROTO and LUIS MOLINA: Sovereign ratings and their asymmetric response to fundamentals.

1429 JUAN ÁNGEL GARCÍA and RICARDO GIMENO: Flight-to-liquidity flows in the euro area sovereign debt crisis.

1430 ANDRÈ LEMELIN, FERNANDO RUBIERA-MOROLLÓN and ANA GÓMEZ-LOSCOS: Measuring urban agglomeration. A refoundation of the mean city-population size index.

1431 LUIS DÍEZ-CATALÁN and ERNESTO VILLANUEVA: Contract staggering and unemployment during the Great Recession: evidence from Spain. 
1501 LAURA HOSPIDO and EVA MORENO-GALBIS: The Spanish productivity puzzle in the Great Recession.

1502 LAURA HOSPIDO, ERNESTO VILLANUEVA and GEMA ZAMARRO: Finance for all: the impact of financial literacy training in compulsory secondary education in Spain.

1503 MARIO IZQUIERDO, JUAN F. JIMENO and AITOR LACUESTA: Spain: from immigration to emigration?

1504 PAULINO FONT, MARIO IZQUIERDO and SERGIO PUENTE: Real wage responsiveness to unemployment in Spain: asymmetries along the business cycle.

1505 JUAN S. MORA-SANGUINETTI and NUNO GAROUPA: Litigation in Spain 2001-2010: Exploring the market for legal services.

1506 ANDRES ALMAZAN, ALFREDO MARTÍN-OLIVER and JESÚS SAURINA: Securitization and banks' capital structure.

1507 JUAN F. JIMENO, MARTA MARTÍNEZ-MATUTE and JUAN S. MORA-SANGUINETTI: Employment protection legislation and labor court activity in Spain.

1508 JOAN PAREDES, JAVIER J. PÉREZ and GABRIEL PEREZ-QUIRÓS: Fiscal targets. A guide to forecasters?

1509 MAXIMO CAMACHO and JAIME MARTINEZ-MARTIN: Monitoring the world business cycle.

1510 JAVIER MENCÍA and ENRIQUE SENTANA: Volatility-related exchange traded assets: an econometric investigation.

1511 PATRICIA GÓMEZ-GONZÁLEZ: Financial innovation in sovereign borrowing and public provision of liquidity.

1512 MIGUEL GARCÍA-POSADA and MARCOS MARCHETTI: The bank lending channel of unconventional monetary policy: the impact of the VLTROs on credit supply in Spain

1513 JUAN DE LUCIO, RAÚL MÍNGUEZ, ASIER MINONDO and FRANCISCO REQUENA: Networks and the dynamics of firms' export portfolio.

1514 ALFREDO IBÁÑEZ: Default near-the-default-point: the value of and the distance to default.

1515 IVÁN KATARYNIUK and JAVIER VALLÉS: Fiscal consolidation after the Great Recession: the role of composition.

1516 PABLO HERNÁNDEZ DE COS and ENRIQUE MORAL-BENITO: On the predictability of narrative fiscal adjustments.

1517 GALO NUÑO and CARLOS THOMAS: Monetary policy and sovereign debt vulnerability. (Revised version: September 2015)

BANCODEESPAÑA

Eurosistema
Unidad de Servicios Auxiliares

Alcalá, 48 - 28014 Madrid

E-mail: publicaciones@bde.es www.bde.es 